\title{
From Molecular Biology to Epithelial Carcinogenesis
}

\author{
FERNANDO MÉNDEZ \\ Facultad de Salud Pública y Nutrición \\ Universidad Autónoma de Nuevo León, México. \\ E-mail addresses: dr.fernandomendez.mx@gmail.com,luis.mendezlop@uanl.edu.mx
}

\begin{abstract}
The theory of the origin of carcinomas suggests that neoplasias from epithelial tissues are the consequence of the reactivation of developmental programs. It proposes a model in which the epithelial cells undergo cellular transitions due to replicative senescence and inflammation towards a mesenchymal-undifferentiated phenotype with cancerous behavior. The conserved pattern of histological progression and the molecular biology of carcinomas is congruent with the view of cancer as a developmental disease. In support of the theory, the experimental literature regarding the molecular, cellular, and histopathological mechanisms associated with epithelial carcinogenesis were aligned according to the premises of the hypothesis. Thereby identified a generic process in the carcinogenesis of the breast, endometrium, prostate, colon, lung, pancreas, bladder, liver, and cervix. Then, is provided a methodology overview of modeling in systems biology derived from previous research testing the hypothesis. The results illustrate the value of the complex systems approach to recover behavior that cannot be inferred only by traditional methods. Specifically, the model suggests that the consistency in the cell types and the directionality of the observed cellular transitions during epithelial carcinogenesis arise from structural constraints in the molecular networks associated with the carcinomas. Overall, the results of the dynamical analysis agree with the premises of the hypothesis and provide an insightful perspective of the potential mechanisms underlying the cellular plasticity displayed during epithelial carcinogenesis. In an era of big data and yet few advances in the underlying causes of chronic diseases, the manuscript also aims to inspire molecular biologists to integrate existing empirical evidence with systems biology modeling in the pursuit of understanding.
\end{abstract}

Keywords: Senescence, EMT, Inflammation, GRN, Attractors, Carcinomas, Cellular plasticity, Convergence

\section{Introduction}

The incidence of carcinomas increases exponentially with age, especially in patients suffering from chronic inflammation. The relationship between aging, inflammation, and tumorigenesis is traditionally understood from the genetic point of view of cancer. In other words, aging and inflammation would increase the chances of developing and accumulating random somatic mutations that eventually generate clones of epithelial cells with cancerous characteristics ${ }^{1}$. In contrast, a painstaking examination of the histological progression of carcinomas in adults suggests a robust pattern of cellular and molecular events that more closely resembles a developmental process than an event generated by chance. Furthermore, the progressive nature of carcinomas is supported by current histological analysis ${ }^{2-4}$. Namely, carcinomas are preceded by atypical hyperplasia that in turn progress from typical hyperplasia. The presence of atypia increases five-fold the risk of developing carcinomas. Therefore, atypical hyperplasia is considered the precursor of carcinoma in situ (CIS), which in turn increases 10 times the relative risk of developing invasive carcinoma. The carcinoma arising from the CIS then progresses from low to high histological grade (G1-G2-G3). The latter is a classification that 
describes the cellular and nuclear characteristics of cells and stages its degree of differentiation ${ }^{4}$. The overall process is reminiscent of the intrinsic cellular plasticity displayed during embryo development ${ }^{5}$. Therefore, events that result in their reactivation in the adult could organize the malignant transformation of the epithelium and its dissemination, which outcome is the lethal metastatic disease. The hypothesis of the origin of carcinomas proposes that the histological progression of carcinomas in adults is the result of discrete cellular transitions undergone by aged epithelial cells in the hyperplasia due to replicative senescence and inflammation towards a mesenchymal-undifferentiated phenotype with cancerous behavior ${ }^{6}$. In this manuscript the hypothesis was rooted in a thoughtful review of empirical evidence from the carcinomas of the breast, endometrium, prostate, colon, lung, pancreas, bladder, liver, and cervix. In addition, is provided an overview of the methodology employed for the construction of a gene regulatory network (GRN) model for epithelial carcinogenesis. The results of its dynamics and predictions were confronted with current evidence in support of the hypothesis. The review also aims to illustrate that systems biology approaches to molecular networks enables to recover a behavior that is useful to comprehend the complex process operating in carcinogenesis.

\section{The carcinogenesis of epithelial tissues}

1.1. The dedifferentiation of carcinomas

Cancer that originates from epithelial tissue is called carcinoma and is the most common type of neoplasia in humans. Up to $85 \%$ of cancer diagnosed in adults begins in the skin, breast, endometrium, prostate, colon, lung, pancreas, bladder, liver, or cervix ${ }^{7}$. In general, epithelial tissues are constituted by two types of cells, the epithelial that line the surface of a tissue or organ and the mesenchymal located in the extracellular matrix. At the microscopic level, they are composed of epithelial cells attached to the basement membrane, which establishes an axis of apical-basal polarity and they communicate with each other through cell-cell interactions. Below the basement membrane is the stroma, which is formed by the three-dimensional extracellular matrix synthesized by the mesenchymal cells. Broadly, epithelia form specialized threedimensional structures adapted to their physiological function, as is the case with secretory organs ${ }^{8}$. Hence, most carcinomas are adenocarcinomas since they originate in the glandular tissue. In fact, the basis for their histological grading is the formation of glands, being the well-differentiated or low-grade adenocarcinomas when $95 \%$ of the tumor are glands (G1), while in poorly differentiated or high-grade carcinomas (G2-G3) less than $50 \%$ is formed by glands. High-grade invasive carcinomas present desmoplasia, that is, a fibroblastic proliferation that surrounds the tumor cells. During the progression of carcinomas occurs an inversion in the ratio epithelium to the stroma. In other words, the content of mesenchymal cells and the expression of their markers increase outnumbering the epithelial proteins. Moreover, the proportion of stromal content is an independent factor of poor prognosis ${ }^{9-12}$.

The natural history of cancers from epithelial origin indicates that aging and inflammation plays a major role in the molecular and cellular events shaping the histological dedifferentiation and the progression of carcinomas. Furthermore, the onset and the aggressiveness of epithelial carcinogenesis is tightly linked to lifestyle factors. A risk factor is any attribute, characteristic, or exposure of an individual that increases the likelihood of developing cancer. The duration and the intensity of the exposition to a risk factor influence the chances for cancer development and the severity of the progression. Other than age, most risk factors for cancer development are considered modifiable. From the critical revision of the carcinomas of the breast, endometrium, prostate, colon, lung, pancreas, bladder, liver, and cervix is provided a prototypical set of events that seem essential for epithelial carcinogenesis. For the sake of clarity, the detailed review of each carcinoma is provided at the end of the manuscript (Box. 2). In the following, is presented the generic role of aging, inflammation, and their relationship with lifestyle for sporadic cancer development. 
1.2. Generic events in the natural history of carcinomas

Epidemiological studies indicate the importance of lifestyle factors in carcinoma development. With the exception of age, the modifiable lifestyle risk factors associated with epithelial carcinogenesis are obesity, metabolic syndrome, hormone therapy, physical inactivity, western diet, smoking, alcohol consumption, and certain infectious diseases ${ }^{7,13-15}$. Therefore, sporadic carcinomas are considered lifestyle diseases where most cases are associated with unhealthy habits or infections. Hence, the policy for cancer prevention focuses on reducing the use of tobacco and alcohol, avoid obesity, the proper management of infections, and dietary advice $^{16}$.

In this contribution, current knowledge was integrated to develop a global picture that links different yet complementary areas of investigation. In a first approximation, the risk factors associated with carcinoma development induce an endocrine profile that increases the levels of growth factors, cytokines, and hormones 17,18 that generate the chronic proliferation of epithelial cells ${ }^{19}$, 20 . Hormones, growth factors, and cytokines strongly synergize their inflammatory and mitogenic effects ${ }^{21,22}$. Most epithelial tissues are highly susceptible to environmental influences and their chronic exposition induces inflammation and conditions associated with benign proliferative disorders ${ }^{23-25}$. Therefore, in this theoretical framework, lifestyle essentially modulates the rate of cellular aging and systemic inflammation ${ }^{6}$.

Consistently, most carcinomas are diagnosed in the fifth decade of life and the higher frequency is reached in the late seventies ${ }^{26}$. Regarding histology, the progression of carcinomas follows a pattern in which adenocarcinomas in situ arise from atypical hyperplasia. Hence hyperplasias are considered the non-obligated precursors of epithelial neoplasias. The diagnosis of atypia increases fivefold the risk of invasive adenocarcinomas ${ }^{26}$, which accounts for $80 \%$ of all invasive lesions ${ }^{27}$. Among the molecular and histological changes occurring in hyperplasias is the increased expression of senescence markers ${ }^{28}$. Then, their infiltration with lymphocytes is a common observation in the progression into carcinoma ${ }^{29}$ and the concomitant reduction of senescent biomarkers ${ }^{30-32}$. The loss of differentiation experienced by carcinomas during the acquisition of higher grades of malignancy is accompanied by the diminution of epithelial histology ${ }^{2,33}$ and increased expression of mesenchymal ${ }^{34}$ and stem cell biomarkers ${ }^{35}$. Final or advanced stages of carcinomas are considered high grade with the presence of metastasis ${ }^{36}$, which frequently affect the bone, lung, liver, or brain and the prognosis is poor with a lack of response to palliative therapy ${ }^{37-39}$.

\subsection{Cells involved in epithelial carcinogenesis}

The set of transcription factors that regulate the gene expression, morphogenesis, and development of epithelial tissues are the ETS (epithelium-specific) proteins. The conserved ETS domain allows direct binding to promoter and enhancer regions of target genes crucial for the proliferation and the formation of cellular interactions between epithelial cells ${ }^{40}$. Among the 26 members of the family, the subgroup called ESE proteins (ETS specific of epithelium) is reserved for epithelial tissues ${ }^{41}$. These transcription factors are ESE1, ESE-2, ESE-3, and the PDEF (Prostate-derived Ets factor). Consistently, it has been found that the silencing or downregulation of the ESE family of proteins is necessary for the loss of differentiation of the epithelial phenotype and the generation of carcinomas ${ }^{42}$.

In the case of hyperplasias, the affected epithelial tissues are enriched with the presence of senescent cells ${ }^{28}$, 43, 44. The molecular machinery of senescence involves the players of DNA damage response, such as the ATM protein kinase (Ataxia telangiectasia mutated) ${ }^{45}, \mathrm{p} 53$, and Chk2 (Checkpoint kinase 2) ${ }^{46}$. However, this cellular phenotype is characterized by the activity of the locus of the inhibitors of kinases (Ink4b/ARF/Ink4a). This locus encodes three genes; the cyclin-dependent kinase inhibitor 2B (CDKN2A / p15), the cyclin-dependent kinase inhibitor $2 \mathrm{~A}$ (CDKN2A / p16), and using an alternative reading frame of p16 (ARF) is enabled the transcription of the ARF protein product of CDKN2A (p14) ${ }^{47}$. The induction of senescence recruits the polycomb proteins $(\mathrm{PcG})$ to the locus Ink4b/ARF/Ink4a ${ }^{48}$. Notably, the dissociation 
of the PcG proteins and the activity of the histone demethylases and methyltransferases play a major role in the reconfiguration of chromatin and the transcriptional capabilities of senescent cells ${ }^{49}$. Then, the transformation of hyperplasias to carcinomas is characterized by a marked diminution of senescent cells 28,43 , whereas in the late stage of carcinoma progression the most abundant cell type in the tumor microenvironment is the fibroblasts. These cells account for the characteristic desmoplasia and dedifferentiation of the high-grade carcinomas ${ }^{50,51}$. The set of transcription factors that seem essential in the maintenance of these phenotypes are the Paired related homeobox 1 (Prrx 1), the paired-related homeobox protein SHOT (Shox2), the AP-1 Transcription Factor Subunit (c-fos), the Snail Family Transcriptional Repressor 2 (Slug), and the Twist family bHLH transcription factor 1 (Twist1) ${ }^{52}$. However, according to the expression of $\alpha$-SMA these cells correspond with myofibroblasts, which possess cellular plasticity and multipotency ${ }^{53}$. During fibrogenesis or desmoplasia, the mesenchymal cells acquire traits of embryonic cells, such as increased expression of the pluripotent marker the octamer-binding transcription factor 4 (Oct4), hypomethylation, and turn highly proliferative ${ }^{53-56}$.

Broadly, the epithelial, senescent, and fibroblastic cells, characterize and sometimes outnumber each step of the histological progression of carcinomas, furthermore, intriguingly they are also involved in the spontaneous immortalization of epithelial cells in vitro.

The study of primary cultures of normal epithelial cells has shown that eventually, they lose the luminal phenotype and epithelial biomarkers to became senescent with the expression of p16. However, over the long term, some senescent cells resume proliferation and adopt the morphology of fibroblasts, with the expression of vimentin 80,57 . Those studies indicate that normal epithelial cells can abrogate replicative cellular senescence and become immortal in vitro but the process requires the adoption of the fibroblastic phenotype. According to the premises of the hypothesis of the origin of carcinoma, both events, the in vivo and in vitro transformation are the result of discrete changes in cellular phenotype driven by cellular aging and inflammation ${ }^{6}$.

\subsection{Cellular transitions and epithelial carcinogenesis}

The conversion of one cell phenotype into another of a different lineage is considered a cellular transition, whereas the switch between somatic cell types through genetic reprogramming is also viewed as an event of transdifferentiation. In this context, the process by which the epithelial cell undergoes replicative exhaustion is considered the first cellular transition. Once senescent, the cell is prone to dedifferentiate into a mesenchymal stem cell phenotype. Several studies in vitro provide evidence of the cellular transitions and the molecular events driving the order among them. For example, the entry to senescence in the epithelial cells is mainly the result of telomere attrition due to the steady proliferation for renewal and the maintenance of functions of epithelial tissues ${ }^{58}$. In each round of cell cycle and DNA replication, the telomeric region is gradually lost until the onset of the signal of genetic damage that originates the cell cycle arrest and the acquisition of the phenotype replicative cellular senescence ${ }^{59}$. Telomere erosion is sensed as a DNA damage response (DDR) ${ }^{60}$, thus, senescent cells show multiple DNA repair foci that are normally associated with double-strand DNA breaks in their telomeres ${ }^{61}$. One of the initial steps in the formation of those complexes is the phosphorylation of the histone family member $\mathrm{X}(\mathrm{H} 2 \mathrm{AX})$ by the ATM protein kinase (Ataxia telangiectasia mutated) ${ }^{45}$, which also activates the proteins p53 and Chk2 (Checkpoint kinase 2) ${ }^{46}$. In turn, p53 activates its transcriptional targets, such as the cyclin-dependent kinase inhibitor 1 (p21) ${ }^{62}$, PML (Promyelocytic leukemia protein) ${ }^{63}$, the locus Ink4b/ARF/Ink4a, and PcG ${ }^{48}$.

The ATM kinase phosphorylates the NF- $\kappa B$ essential modulator (NEMO), which in turn, induces NF- $\kappa B$ activity ${ }^{64}$. The senescent cells eventually increase the secretions of cytokines, chemokines, growth factors, and proteases ${ }^{65}$ which its expression was found to be coordinated by the transcription nuclear factor kappa B $(\mathrm{NF}-\kappa \mathrm{B}){ }^{66}$. The constant activation of the DDR increases the secretion of proinflammatory cytokines and 
ignite a positive inflammatory signaling loop, that has been associated with the perpetuation of the proliferative signaling and the acquisition of mesenchymal stem traits ${ }^{64}$.

Increasing evidence links inflammation over senescent cells with eventual epithelial to mesenchymal transition (EMT) and the transformation from the flat cell phenotype into a fibroblast morphology and the upregulation of the mesenchymal biomarkers ${ }^{67}$. The capacity of the soluble mediators of inflammation to induce EMT in cell lines derived from carcinoma has been reviewed extensively ${ }^{68}$. The cytokines tumor necrosis factor-alpha (TNF- $\alpha$ ), the transforming growth factor beta (TGF- $\beta$ ), interleukin 1-beta (IL-1 $\beta$ ), and the interleukin 6 (IL-6) converge in the activation of the transcription factor NF- $\mathrm{kB}{ }^{69-71}$, which constant stimulation upregulates the expression of Snail, Slug, Twist, Zeb and the Forkhead Box C2 (FOXC2). In turn, the mesenchymal transcription factors repress the locus Ink4b/ARF/Ink4a and the ETS transcription factors to stabilize the fibroblastic phenotype ${ }^{72-74}$. The abrogation of cellular senescence by EMT generates mesenchymal cells with the expression of the set of pluripotent genes, such as, SRY-Box Transcription Factor 2 (SOX2), the homeobox pluripotency transcription factor (Nanog), the octamer-binding transcription factor 4 (Oct4), the RNA-binding protein that regulates mRNA translation in embryonic stem cells (Lin28B), and the neurogenic locus notch homolog protein 1 (Notch1) ${ }^{75,76}$. The process of EMT explains the cancer stem cell phenotype ${ }^{77}$, the resistance to chemotherapy ${ }^{78,79}$, the immune system evasion, and the ability to induce tumors and their heterogeneity ${ }^{80}$. Overall, cellular aging justifies the entry of epithelial cells into senescence, then cellular inflammation induces the EMT of aged cells into mesenchymal stem cells primed for cancer behavior. According to the hypothesis of the origin of carcinomas, the progressive nature of carcinomas is mirroring the spontaneous immortalization of epithelial cells in vitro, in other words, discrete transitions between cell phenotypes (Fig. 1.).

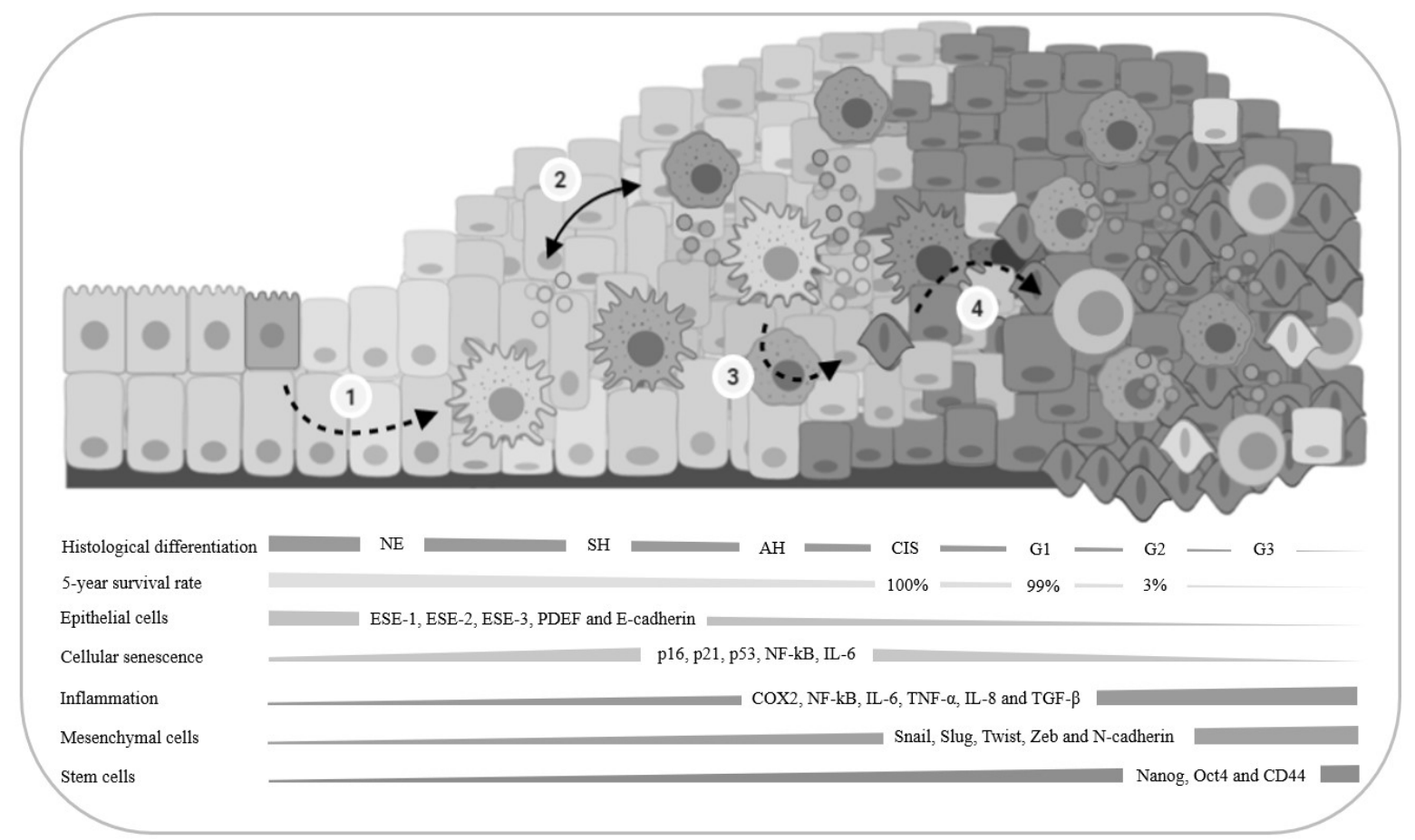

Fig. 1. Cellular transitions shaping epithelial carcinogenesis. The hypothesis considers that the persistent proliferation of epithelial tissues to cope with the maintenance of their functions eventually generates an increased content of senescent cells (1). Then, hyperplastic lesions are infiltrated by immune cells (2) that induce EMT of senescent cells in vivo (3). Cells that emerge acquire fibroblastic and embryonic traits (4) and the ability to induce carcinomas. Bars illustrate the changes that characterize each process and its relative abundance during carcinoma progression in the context of the histological stage (In Box. 2 the detailed review is provided). NE; Normal Epithelium, SH; Simple Hyperplasia, AH; Atypical Hyperplasia, CIS, Carcinoma in situ, G; Grade. 
In this theoretical framework, lifestyle modulates the rate of replicative exhaustion of the parenchyma in epithelial tissues. Therefore, these conditions lead to changes in epithelia that result in the histology associated with hyperplasia and the entry of epithelial cells into senescence. The accumulation of senescent cells in turn induces the infiltration of immune cells that allow the abrogation of senescence by EMT induced by inflammation. Thus, explaining the association of the progression of the atypical hyperplasia with the infiltration of immune cells. Hence, an increased burden of conditions fostering the mentioned cellular transitions leads to progression into higher grades of dedifferentiation and explains the association of mesenchymal and stem biomarkers with overall adverse prognosis ${ }^{6}$. In summary, emerges a plausible scheme of the origin of carcinoma by a series of cellular transitions in vivo. Dynamic models are suitable to test this type of hypothesis and helps to understand the concept of cellular transition since actually recover behavior from molecular networks that cannot be inferred from traditional approaches. The following provides an overview of modeling epithelial carcinogenesis with systems biology.

\section{Cancer systems biology}

\subsection{Gene regulatory networks}

The traditional approach to the molecular biology of cancer relies on linear descriptions of causality involving a small number of elements. However, those strategies are insufficient to describe elaborated networks of molecular interactions that exhibit non-linear dynamics. With tools of systems biology is possible to combine the results of empirical experiments in networks to calculate and model biological relationships to gain an understanding of the principles that operate during carcinogenesis ${ }^{81}$. In addition, cellular transitions are suited for this type of analysis since the discrete change between cellular phenotypes is the result of the concerted action of many genes ${ }^{82}$. In a first approximation, cellular phenotypes are discrete entities originated from the stable expression of a set of genes and a specific group of proteins that characterize their unique morphology and functions. Another consideration is that transcription factors account for most of the gene expression profile observed in a certain cell type since those proteins regulate massive transcriptional events and specify the expression of genes associated with a cellular phenotype while repressing the activity of transcription factors from other lineages. Furthermore, a large body of evidence showed that the ectopic expression of these proteins is sufficient to induce the transdifferentiation of somatic cells by recruiting enzymes that result in chromatin remodeling and the attainment of different cell phenotype with a stable epigenetic configuration. Currently, is estimated that the human genome is organized by the activity of 1,500 transcription factors that bind specific DNA regulatory sequences to enable the differential expression of the 24,000 protein-coding genes to determine a specific transcriptome that generates approximately 200 unique cell types with different functions and morphology ${ }^{83}$.

Transcription factors that act collectively interacting with each other are also called gene regulatory networks (GRNs) and are mechanistically linked with the organization of cell fates. Furthermore, these modules are considered responsible for the differential gene expression during the process of developmental or cell differentiation (Fig. 2.) ${ }^{83}$. Since a biological system can be described as a network, to construct a GRN model the knowledge from molecular biology is captured in nodes and its interactions in the form of edges. Hence, the fundamental framework of systems biology is the graph theory in which the complexity of a biological system is described, analyzed, and modeled using mathematical language ${ }^{81}$. Hence, it is possible to integrate the actions of the molecular components of the GRN and to follow their dynamics to describe the biological phenomenon from another perspective ${ }^{84}$. Often, the molecular interactions translate into emergent properties that correlate with cell behavior. This allows novel approaches for a deeper understanding of the mechanisms by which GRNs coordinate stable phenotypes and the cellular transitions among them during the events of differentiation or transdifferentiation ${ }^{85}$. To construct a GRN model is preferred to consider mainly transcription factors as the nodes and their type of interactions should reflect the reported molecular regulation. The generated graph illustrates that regulatory interactions among the transcription factors impose 
constraints in the collective dynamics of gene expression. In other words, only a few gene expression patterns are allowed in which the interactions of all elements are satisfied, and the system reaches equilibrium. These steady states are called attractors and correspond to the gene expression profiles associated with a cellular phenotype ${ }^{86}$.

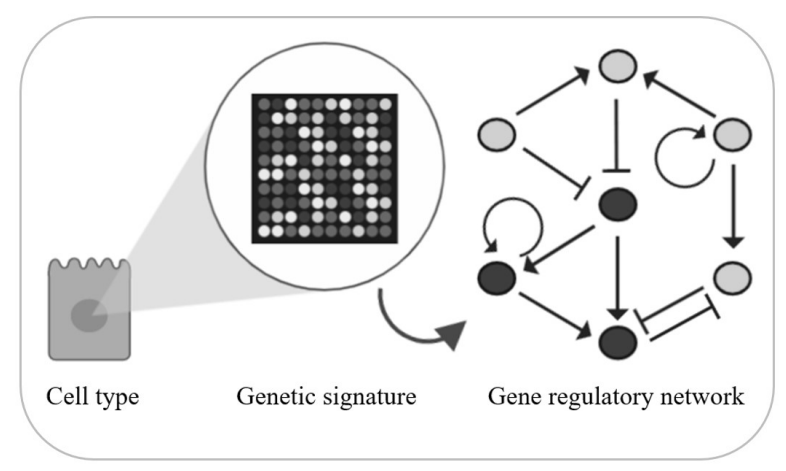

Fig. 2. Cellular phenotypes correlate with a specific configuration of the GRN. Differentiated cells possess an epigenetic profile that results in unique transcriptional activity. The transcription factors conform GRNs that organize the attainment of several stable states that correspond with the gene expression profiles associated with every cell type. Therefore, a stimulus that increases the activity of key transcription factors in the GRNs could induce a discrete switching between phenotypes and provides a theoretical foundation for cellular transitions. GRNs for the study of differentiation and developmental events can be constructed from data from transcriptomic studies or from molecular interactions of biomarkers that give the identity of the cellular phenotypes.

The term multistability refers to the ability of the GRNs to produce more than one attractor and its consistent with the capacity of the genome to produce several cellular phenotypes from the same information. The unstable states surrounding each attractor represent its basin of attraction and the complete set of possible configurations of the GRN is called the state space ${ }^{86}$. The boundaries between the basins of attraction compartmentalize the state space and generate the epigenetic landscape. This substructure imposes dynamic constraints that govern the temporal order of transitions between the attractors produced by the GRN. Therefore, these models are useful for studying the processes of differentiation and development. Since each cell fate is associated with an attractor, a cell transition would correspond to the change between attractors ${ }^{84}$. In this theoretical framework, the growth factors, hormones, cytokines, radiation, mechanical forces, or other external or internal signals can disrupt the state of the GRN by inducing the activity of some nodes and could lead to new basins of attraction and generate a change in the phenotype. Hence, changes in the GRN activity induce cellular transitions and potentially modify the epigenetic landscape. Under this view, the cellular plasticity operating during epithelial carcinogenesis is naturally embraced. The following section presents the results of the dynamic modeling of the hypothesis using Boolean formalism.

\subsection{Testing the hypothesis with Boolean formalisms}

Boolean models are the simplest mathematical formalism for studying the qualitative temporal behavior of GRNs and the effect of perturbations on their dynamics. Boolean models consist of a set of nodes whose state is binary and is determined by other nodes in the network through Boolean functions (Box. 1.) ${ }^{87}$. These models are suitable for the evaluation of hypotheses and in a first approximation, every phenotype involved with the process of epithelial carcinogenesis would be determined by a specific configuration of the GRN, while the order of the transition between attractors could be associated with the directionality of the progression. 


\section{Box. 1. Overview of the construction of a dynamic model for carcinomas}

Dynamical models of GRNs are effective in describing complex biological phenomena such as cancer development. To generate a dynamic model for the study of epithelial carcinogenesis was necessary to identify the molecular biomarkers that characterize the recurrent cellular phenotypes in the process and their form of interaction based on experimental data. The information was then incorporated in the architecture of the network that is composed of nodes, links, and their positive or negative modality of interaction (Fig. 3.)

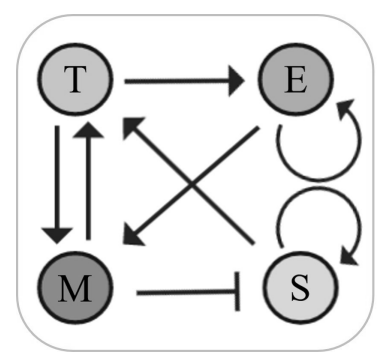

Fig. 3. Structure of a GRN

The data of the interaction between the nodes of the GRN is used as Boolean functions. These nodes can only take the value 1 or 0 to represent whether the gene is expressed or repressed respectively (Table 1).

Table 1. Boolean functions

\begin{tabular}{|c|c|c|c|c|c|c|c|c|c|c|c|}
\hline \multicolumn{3}{|c|}{$\begin{array}{c}\text { Totipotent } \mathrm{Tf} \\
\text { (or) }\end{array}$} & \multicolumn{3}{|c|}{$\begin{array}{c}\text { Epithelial }{ }_{\mathrm{Tf}} \\
\text { (or) }\end{array}$} & \multicolumn{3}{|c|}{$\begin{array}{c}\text { Mesenchymal }_{\mathrm{Tf}} \\
\text { (and) }\end{array}$} & \multicolumn{3}{|c|}{$\begin{array}{l}\text { Senescent } \mathrm{Tf} \\
\text { (not if) }\end{array}$} \\
\hline \multicolumn{2}{|c|}{ Inputs } & \multirow{2}{*}{$\frac{\text { Output }}{\mathrm{T}}$} & \multicolumn{2}{|c|}{ Inputs } & \multirow{2}{*}{$\frac{\text { Output }}{\mathrm{E}}$} & \multicolumn{2}{|c|}{ Inputs } & \multirow{2}{*}{$\frac{\text { Output }}{\mathrm{M}}$} & \multicolumn{2}{|c|}{ Inputs } & \multirow{2}{*}{$\frac{\text { Outpu }}{\mathrm{S}}$} \\
\hline M & $\mathrm{S}$ & & $\mathrm{T}$ & $\mathrm{E}$ & & $\mathrm{T}$ & E & & M & $\mathrm{S}$ & \\
\hline 0 & 0 & 0 & 0 & 0 & 0 & 0 & 0 & 0 & 0 & 0 & 0 \\
\hline 0 & 1 & 1 & 0 & 1 & 1 & 0 & 1 & 0 & 0 & 1 & 1 \\
\hline 1 & 0 & 1 & 1 & 0 & 1 & 1 & 0 & 0 & 1 & 0 & 0 \\
\hline 1 & 1 & 1 & 1 & 1 & 1 & 1 & 1 & 1 & 1 & 1 & 0 \\
\hline
\end{tabular}

In a Boolean GRN model the state of expression of each gene changes along time according to the dynamic equation:

$$
x(t)=\mathrm{S}(t)=[x 1, x 2, \ldots, x N]
$$

The solution of this equation is the movement of the state vector $\mathrm{x}$ in the $N$-dimensional gene expression state space. Then, the GRN is modeled as a dynamic system to recover the attractor states which configuration should be compared with the expected cellular phenotypes. The state space generates a characteristic substructure that imposes restrictions on the dynamics of the network. This is compartmentalized by the boundaries between the attraction basins and leads the unstable states towards the attractors (Fig. 4.). 


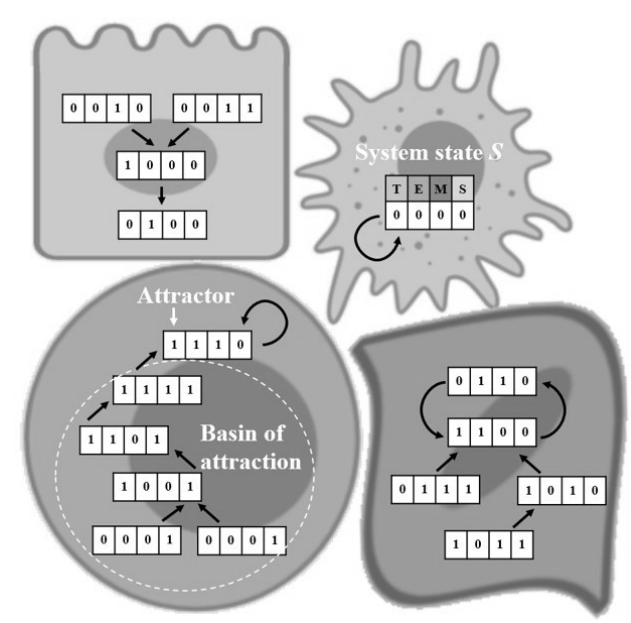

Fig. 4. State Space

With the use of a stochastic version of the Boolean model, it is possible to explore the order in which the system converges to the different attractors. In this model, a constant probability of error $\xi$ is introduced for the deterministic Boolean functions. In other words, at each time step, each gene disobeys its Boolean function with probability $\xi$, according to the equation:

$$
P_{x i(t+1)}\left[F_{i}\left(\mathrm{x}_{\text {regi }}(t)\right]=1-\xi\right.
$$

Therefore, enables the study of the properties of the epigenetic landscape emerging from the interactions of the molecular actors in the GRN and to understand the transitions between cellular phenotypes during carcinogenesis. Hence, a cellular transition can be viewed as a switch of the system state that results in a change of an attractor or the basin of attraction from another attractor (Fig. 5.).

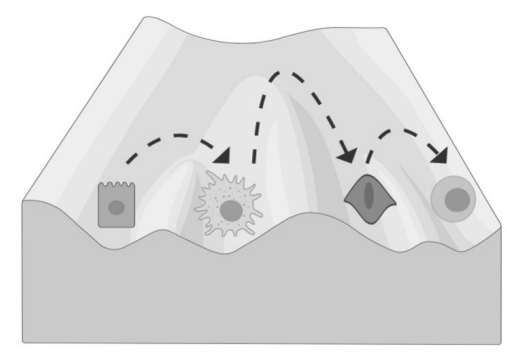

Fig. 5. Epigenetic landscape

The GRN model of the hypothesis of epithelial carcinogenesis was conceived considering the molecular players responsible for the epithelial, senescent, and mesenchymal phenotypes as well as the processes of replicative senescence and EMT induced by proinflammatory cytokines. The dynamic analysis of the GRN recovered three attractors that match the gene expression profile expected for the epithelial, senescent, and mesenchymal cells (Fig. 6.a). Furthermore, the analysis of the epigenetic landscape revealed that the highest probability of transition between attractors correlates with the temporal order postulated by the hypothesis. In other words, the epithelial cells first become senescent, and from the latter emerges the phenotype of mesenchymal stem cells that is proposed as the cell state with carcinogenic properties. Remarkable, the model also suggests that the epigenetic landscape changes as a result of proinflammatory conditions, increasing the basin of attraction of the mesenchymal phenotype (Fig. 6.b) ${ }^{88}$. 
a)

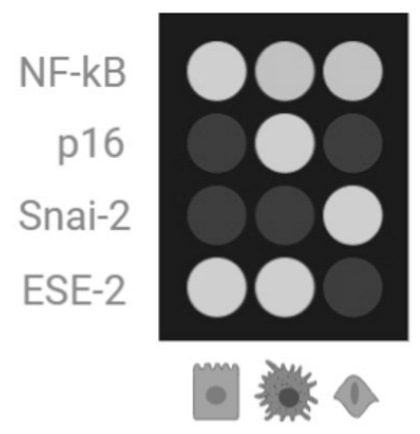

b)

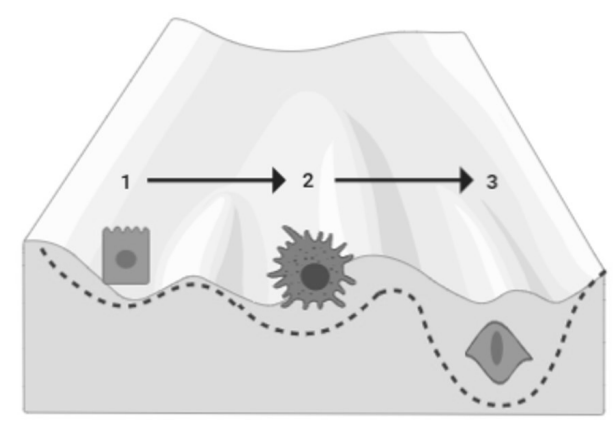

Fig. 6. Representation of the results from the Boolean model of the GRN of epithelial carcinogenesis. a) The model recovered three attractors that matched the gene expression profile that characterize cells with an epithelial, senescent, and mesenchymal phenotype. b) The analysis of the Epigenetic Landscape indicated that the most probable order of attractor attainment is epithelial, senescent, and mesenchymal and that inflammation increases the basin of attraction of the mesenchymal phenotype.

The predictions of the model were consistent with empirical results, for example, a recent study on the effect of inflammation on epithelial cells found that their incubation in the presence of IL-6 induces proliferation and eventually cellular senescence. Then, in response to the increased concentration of cytokines, a positive autocrine loop of inflammation is initiated, and cells emerge through induction of EMT with the morphology of fibroblasts. These cells also showed the functional properties of migration, invasion, and sphere formation. Furthermore, their exposure to high levels of inflammatory cytokines was a requirement for the maintenance of stemness ${ }^{89}$.

The model suggests that the generic series of cell transitions among the epithelial, senescent, and mesenchymal cells governs the loss of differentiation during carcinogenesis as the emergent result of restrictions in the endogenous GRN. In other words, provides a non-linear dynamic perspective of the mechanism by which aging and inflammation induce carcinomas and the spontaneous immortalization of epithelial cells. In a simple way, it suggests that aging and inflammation underlie the directionality of the malignant transformation of the epithelia towards dedifferentiation and metastasis. Moreover, for the first time provided a non-mutagenic explanation for the role of cellular senescence and chronic inflammation with the emergence of sporadic carcinomas ${ }^{88}$.

The model recovers well-known cellular phenotypes involved in carcinomas that were easy to correlate with the empirical evidence available seven years ago, however, the attractors generated under conditions of overexpression were hard to understand back then. For example, the simulation of constitutive cellular senescence produced three attractors showing cellular inflammation and epithelial, mesenchymal, or hybrid phenotypes respectively (Fig. 7.a), and with the simulation of overexpression of epithelial interactions, or downregulation of inflammation the model recovered an epithelial phenotype (Fig. 7.b). Current evidence clarifies the unknown attractors and highlights the predictive capacity of modeling. At present is well characterized that the molecular events induced by senescence in epithelial cells are similar to a DDR response and involve cellular inflammation ${ }^{66}$, hence matches the attractor of senescent epithelial cells. The second phenotype predicted by the model is a senescent cell with mesenchymal biomarkers; a profile observed in the elusive myofibroblast. Interestingly, these cells are detected in preneoplasic lesions, chronic inflammatory conditions, and desmoplasia in carcinomas ${ }^{53,90}$. Furthermore, ongoing understanding indicates that most myofibroblasts emerge from EMT in those conditions ${ }^{91}$. The third attractor produced by the simulation of cellular senescence produced senescent hybrid phenotypes. Interestingly, this attractor emerges also from the simulation of inflammation and growing evidence shows that cells responsible for tumor growth 
and cell heterogeneity in vivo display hybrid phenotypes. In other words, neither full EMT nor entirely MET, but cells with multilineage properties are the most malignant ${ }^{92}$. Consistently, senescence is now viewed as a transient form of plasticity in which cells eventually resume proliferation and contribute to the morphogenesis of tissues ${ }^{93}$. Likewise, cells that undergo senescence experience epigenetic changes that make them prone to stemness and to malignant transformation ${ }^{94}$. Finally, the hybrid phenotypes and the malignant potential of senescent cells are also in line with the notion that stemness is the result of transcriptional hyperactivity, multilineage expression, and cell plasticity ${ }^{95}$. Hence, cellular aging and inflammation link stemness to malignancy, and by doing so, suggest the mechanistic basis for tumor reversion ${ }^{6}$.

a)

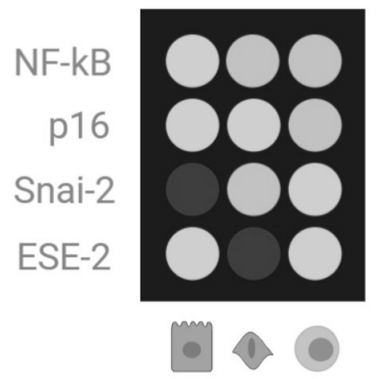

b)

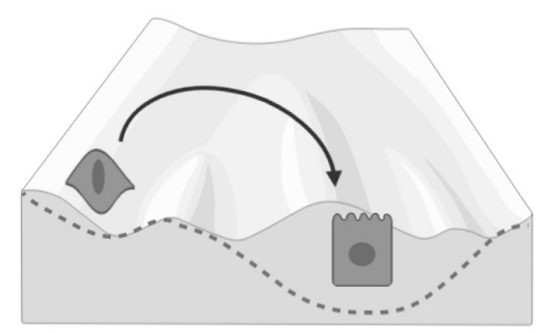

Fig. 7. The simulation of senescence and epithelial interactions in the GRN model. a) Constitutive p16 activation recovers three attractors with intracellular inflammation that matches the biomarkers present in the senescent epithelial cells, the myofibroblasts, and the hybrid phenotypes with stem and malignant behavior. b) The simulation of epithelial interactions or downregulation of inflammation recovers the epithelial phenotype and correlates with the mechanism of metastasis formation and recent empirical evidence of the reversion of the malignant phenotype with anti-inflammatory agents.

The overexpression of epithelial proteins or ablation of inflammation in the model recovers attractors with an epithelial phenotype. In this regard, growing empirical evidence has shown that exposure to high levels of inflammation is a requirement for the maintenance of stemness and malignancy. Furthermore, the elimination or reduction of inflammation restores the epithelial phenotype ${ }^{89}$. A similar phenomenon was documented with the endogenous inflammation at play during cellular senescence. Namely, the ATM kinase induces NF$\kappa \mathrm{B}$ activity and confer mesenchymal stem traits ${ }^{64}$, but the suppression of its transcriptional activities restored the epithelial phenotype ${ }^{96}$. In line with this evidence, recent studies found that changes in the microenvironment enable the mesenchymal to epithelial transition (MET) of tumor cells and offers a compelling understanding of the mechanism underlying the epithelial phenotype of metastasis ${ }^{97,98}$. The process of MET is triggered by the interaction of cells with the parenchyma of the lungs and bones. At the molecular level, the reversion of EMT involved the negative regulation of the mesenchymal transcription factors product of the downstream signals of the microenvironment while the epithelial proteins are activated 99, 100. The modern conceptualization of the molecular, phenotypical, and dynamical changes that undergo tumor cells during carcinogenesis is referred cellular plasticity. It became more accepted that the interplay among microenvironmental cues, genetic or epigenetic alterations and treatment shapes cancer emergence and progression. Furthermore, is considered that targeting cancer plasticity is a promising strategy that might lead to novel anticancer treatments ${ }^{101}$.

\section{Conclusion}

The last 50 years of cancer research have been characterized by a constant increase in the heterogeneity and complexity of its cellular and molecular biology, so the search for generic patterns and the use of simple Boolean models might seem counterintuitive. Although is well known that descriptive models are 
approximations and are essentially incorrect, as a proof of principle, the present manuscript showed that is possible to capture understanding from a different perspective by sacrificing details and using tools from systems biology. In addition, the thoughtful analysis of the histological progression of nine carcinomas revealed a conserved process that might order the malignant transformation of epithelial tissues. In support of the theory, the conserved pattern of histological progression and the molecular biology of carcinomas is congruent with the view of cancer as a developmental disease. Moreover, the dynamical model, suggests that the directionality of progression towards dedifferentiation and the formation of metastasis might result from constraints in the GRN that govern the cellular transitions and their interplay with microenvironmental cues. From a mechanistic perspective, supports that cancer cells mostly arise from senescent cells, and links hyperplasia with cellular senescence and inflammation from a different angle. The model was consistent with the premises of the hypothesis of the origin of carcinomas and proposes a basis for the emergence of enigmatic entities such as the myofibroblasts and the hybrid phenotypes. Finally, the insights of the model are accordant with the modern concept of cellular plasticity in cancer and indicate that cellular aging and inflammation account for most events underlying carcinogenesis and suggest novel approaches for antineoplastic therapy.

\section{Acknowledgments}

The author is grateful to Universidad Autónoma de Nuevo León, FASPYN and CONACYT for current support. He would like to thank colleagues for countless discussions during his tenure at the University of Cagliari, the Center of Complexity Sciences (C3, UNAM), the Biomedical Research Center of Northeast (IMSS), the Max Planck Institute for Biology of Ageing, and the School of Biological Sciences (UANL). The content is solely the responsibility of the author and does not necessarily represent the official views of the institutions.

\section{Box. 2. Conserved process in epithelial carcinogenesis}

\section{Breast Cancer}

Breast cancer is the leading cause of mortality from cancer in women. Epidemiological studies indicate that the most relevant risk factors for the development of this carcinoma are age, obesity, metabolic syndrome, hormonal therapy, physical inactivity, the Western diet, smoking, and alcohol consumption ${ }^{7,13-15}$. They also point to the carcinogenic effect of chronic exposure to high levels of insulin, IGF-1, pro-inflammatory cytokines such as IL-8, IL-6, leptin, and estrogens ${ }^{17,18}$. The effects of this endocrine environment in the glandular epithelium of the breast include increased proliferation and the production of pro-inflammatory cytokines 19, 20. In addition, estrogen, growth factors, and inflammation generate synergistic effects on proliferation and a positive loop in their own transcription 21, 22. The mammary gland is particularly susceptible to environmental influences and inflammatory conditions, that in turn are associated with changes in tissue that lead to breast diseases such as benign proliferative or inflammatory disorders ${ }^{23-25}$. Progression to breast cancer occurs frequently in the fifth decade of life, and $80 \%$ of diagnosed women possess an associated risk factor. Although its clinical detection increases exponentially after menopause, the highest point is reached at the average age of $79^{26}$. Usually, patients under the age of 50 are diagnosed with low-risk tumors whereas patients older than 70 possess high-grade carcinomas ${ }^{102}$. In line with the progressive nature of mammary gland carcinogenesis, atypical hyperplasias are considered precursors of ductal carcinomas in situ. Moreover, the diagnosis of these hyperplasias is associated with five times increased risk of developing invasive ductal carcinoma of the breast ${ }^{25}$. At the time of diagnosis up to $80 \%$ of breast cancers corresponds with that histology ${ }^{27}$. Among the recurrent molecular and histological changes in the hyperplasias before their progression to carcinomas is the expression of the markers of cellular senescence such as the p16 protein ${ }^{28}$, telomere attrition, and lymphocyte infiltration ${ }^{29,30}$. In contrast, invasive carcinomas show an increase in telomeric regions, telomerase reactivation ${ }^{31}$, and downregulation of $\mathrm{p}^{2} 6^{32}$. Progression towards higher 
histological grades, also named the apocrine stages of invasive breast carcinomas are accompanied by the loss of luminal histology and biomarkers of breast epithelial differentiation such as proteins ER, PR, and ecadherin 2, 33. The progression is also illustrated by the acquisition of hormone independence that characterizes the triple-negative phenotype, the presence of metastasis, and the expression of mesenchymal transcription factors, associated with the induction of EMT ${ }^{34}$ and with the gain of cancer stem cells markers such as CD44 ${ }^{35}$. The cells that emerge from EMT display increased resistance to drugs, immunotherapy, and radiotherapy ${ }^{36}$. It has been shown that the repression of the mesenchymal transcription factor Twist is sufficient to inhibit the ability of breast carcinoma cells to colonize the lungs ${ }^{34}$. In addition, cells with stem cell markers derived from breast carcinomas generate tumors with histological heterogeneity of the original mass ${ }^{103}$. Patients diagnosed with high-grade and metastatic breast cancers progress rapidly despite proper administration of palliative therapy or chemotherapy. The prognosis is unfavorable, with an average relative survival rate of 13 months ${ }^{37}$. Metastases mostly affect the bones, lungs, brain, and liver ${ }^{38}$. However, the presence of liver metastasis is associated with the worst prognosis with an estimated survival of one month on average $^{39}$.

\section{Endometrial Cancer}

Endometrial cancer is the most common invasive gynecologic neoplasm in women. The risk of endometrial carcinoma is positively correlated with advanced age, obesity, estrogen use, polycystic ovary syndrome, Western diet, and smoking ${ }^{104}$. The endometrium is very sensitive to estrogen levels and metabolic diseases associated with obesity such as hypertension, diabetes, and dyslipidemia. In fact, the endocrine profile of patients at risk of endometrial cancer is characterized by elevated levels of insulin, estrogens, EGF, IL-18, IL6, leptin, IGF-1, and hyperglycemia ${ }^{105-107}$. This hormonal environment generates pro-inflammatory and mitogenic effects in endometrial cells and eventually those patients develop proliferative endometrial lesions such as hyperplasia and pelvic inflammatory diseases ${ }^{108}$. Chronic exposure to these endocrine conditions increases the risk for malignant transformation; on average, endometrial carcinoma is diagnosed at 61 years of age. The highest incidence is reached at 79 years but obesity is associated with early endometrial carcinogenesis; on average the diagnosis among this population is 50109,110 . The precursor lesion of endometrial adenocarcinoma is the atypical endometrial hyperplasia, characterized by the expression of biomarkers of senescence such as the p16 protein ${ }^{111}$. The gradual loss of biomarkers of senescence and the infiltration of immune cells are associated with their progression to carcinoma ${ }^{112,113}$. In turn, the carcinoma in situ of the endometrium; also called intraepithelial neoplasia, progresses in some cases in less than a year to endometrial adenocarcinoma ${ }^{114}$. Among the molecular events associated with the progression of carcinomas in situ is the gain in the expression and activity of telomerase, as well as the extension of telomeres ${ }^{115-117}$. The $80 \%$ of sporadic endometrial adenocarcinomas show endometrioid histology ${ }^{114}$. However, they eventually progress and generate metastasis that correlates with loss of differentiation and the negative regulation of the hormone receptors, leptin, and E-cadherin ${ }^{3,118}$. On the contrary, vimentin expression, mesenchymal transcription factors, and cancer stem cell markers are increased. In endometrial carcinoma, EMT has been associated with all events of progression ${ }^{119}$. Cells emerging from EMT show expression of the CD133 marker and have the ability to self-renew, migrate, and increased drug resistance ${ }^{120}$. When transplanted into nude mice, they generate heterogeneous cell-enriched tumors that include populations with the mesenchymal markers ${ }^{121}$. The 5-year relative survival rate for localized endometrial cancer is $95 \%$; while women diagnosed with advanced or recurrent disease have an unfavorable prognosis with a survival rate of $17 \%$. The estimated response rate for chemotherapy in advanced endometrial adenocarcinoma is 4 to 9 months. Typical sites for metastasis are the pelvic lymph nodes, vagina, peritoneum, lungs, and less common the liver, bone, and brain metastases ${ }^{122-124}$.

\section{Prostate Cancer}

Prostate cancer is the fifth leading cause of death from neoplasms and is associated with modifiable risk factors that include obesity, androgen levels, the Western diet, consumption of processed meat and dairy 
products, sexually transmitted diseases, and smoking ${ }^{125,126}$. These conditions propitiate increased circulating levels of sex hormones, insulin, Il-6, and IGF-1 125, 127. In turn, this endocrine environment induces proliferation of the prostatic epithelial cells and enhances their secretion of growth and inflammatory factors 128-130. Histologically, a hormonal environment related to the metabolic syndrome or in response to infection

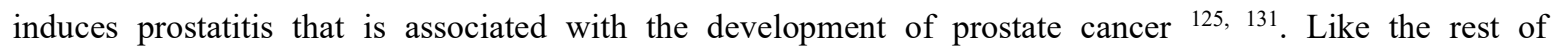
carcinomas, age plays a crucial role in prostatic carcinogenesis; $80 \%$ of young patients show normal histology, infection, or benign inflammatory processes in the prostate, in contrast up to $34 \%$ of elderly present preneoplastic or neoplastic lesions. On average, prostatic carcinoma is diagnosed at 65 years ${ }^{132}$, but, it is estimated that by the eighth decade of life is present in half of men ${ }^{133}$. The precursor lesion of prostate carcinoma is benign prostatic hyperplasia, which progresses to prostatic intraepithelial neoplasia ${ }^{134}$ that increases 15 times the risk of being subsequently diagnosed with cancer ${ }^{135}$. High-grade intraepithelial neoplasia is characterized by the presence of cells with short telomeres ${ }^{136}$, the expression of SA- $\beta$-Gal ${ }^{137}$, p14 and p16 ${ }^{138}$. However, its malignant transformation is associated with the infiltration of immune cells ${ }^{139}$, a diminution of senescent cells ${ }^{140}$, and the reactivation of telomerase activity ${ }^{141,142}$. Up to $95 \%$ of those lesions could progress to a prostate carcinoma with a luminal phenotype ${ }^{143}$, yet, eventually can dedifferentiate and lose the biomarkers and architecture of the epithelia ${ }^{128}$. The stages of high histological grades are associated with EMT, increased expression of mesenchymal transcription factors, androgen independence, and the presence of metastasis ${ }^{144}$. The loss of differentiation of tumor glands is accompanied by the expression of $\mathrm{N}$-cadherin, immune evasion mediated by the enzyme indoleamine 2, 3-dioxygenase, and the presence of regulatory $\mathrm{T}$ cells ${ }^{145}$. In patients with prostate cancer on androgen deprivation therapy, the EMT is associated with the development of hormone independence, drug resistance, the presence of stem cell markers, and death from prostate cancer ${ }^{146}$. The protein CD44 is a biomarker of cancer stem cells produced by the process of EMT in prostate cancer, relapse, the detection of distant metastases, and overall poor prognosis 147,148 . The 5-year relative survival rate for localized tumors is $100 \%$, however, patients on androgen deprivation therapy can progress, and the prognosis with metastatic disease is unfavorable with an average survival of 14 months. The most common sites for prostate cancer metastases are lymph nodes, viscera, and bones, being this last one associated with a more aggressive behavior ${ }^{149}$.

\section{Colon Cancer}

Colon cancer represents the second leading cause of death from cancer, and its development is linked with lifestyle factors such as obesity, the Western diet, smoking, alcohol, and high consumption of processed meat 150. These habits generate an increase in the levels of insulin, leptin, IGF-1, glucose, and proinflammatory cytokines ${ }^{151}$. Chronic exposure to high concentrations of IGF-1 ${ }^{152}$, IL- ${ }^{153}$, leptin ${ }^{154}$, heterocyclic amines, and saturated fats ${ }^{150}$ exerts a carcinogenic role in the colon. The epithelium of the colon is sensitive to the proliferative effects of IGF-1 ${ }^{152}$, and IL-6 ${ }^{155}$, whereas saturated fats ${ }^{156}$ and heterocyclic amines induce damage due to the increase in the production of reactive oxygen species that generate proliferation to repair tissue damage ${ }^{157}$. The chronic presence of unhealthy habits is associated with the development of inflammatory bowel diseases such as colitis ${ }^{158}$, which can precede the diagnosis of colon cancer by up to 30 years ${ }^{159}$. The time of diagnosis is on average at 72 years, but $10 \%$ are detected before 55 and the highest peak of diagnosis is reached at $88^{160}$. Of notice, diagnosis before 40 years of age is associated with a more aggressive tumor biology ${ }^{161}$ and a half patients diagnosed with hyperplastic polyps might develop colon carcinoma within the same year ${ }^{158,162}$. The expression of biomarkers of cellular senescence, the positivity of the p16 protein, the infiltration of lymphocytes ${ }^{111}$, and the shortening of telomeres are common phenomena as the atypia of the hyperplasias increases ${ }^{163}$. Upon progression is observed the recovery of the activity of the enzyme telomerase ${ }^{164}$ and $90 \%$ of histological diagnoses corresponds with colon adenocarcinoma ${ }^{158}$. Like the rest of the carcinomas, eventually evolves to a higher histological grade with loss of glandular architecture, the expression of E-cadherin, and other characteristics associated with differentiation ${ }^{165}$. Highgrade entities overexpress the TGF- $\beta$, SNAIL, Twists, and ZEB1 proteins that correlate with the presence of distant metastases, cancer stem cells, and overall poor prognosis ${ }^{166-170}$. Colorectal cancer cells that undergo 
EMT exhibit properties of mesenchymal stem cells and cancer stem cells, and express Snail, CD133, and CD44 proteins. These cells are highly tumorigenic, metastatic, chemoresistant, and radioresistant ${ }^{171,172}$. In the case of colorectal cancer, an overlap was reported between the genetic programs from those that emerge from EMT and cells isolated as cancer stem cells ${ }^{173}$. The prognosis of patients diagnosed with localized disease is favorable, with a relative 5-year survival rate greater than 90\%. However, patients will develop metastases, $70 \%$ of them in the liver due to the anatomical position concerning the portal circulation and the rest in the lungs, bones, or the brain. The most unfavorable metastatic location for prognosis is the brain, with an average survival of 5 months ${ }^{174,175}$.

Lung cancer

Lung cancer is the most common cause of death from neoplasms and the main risk factor is smoking; however, in the case of non-smokers, the contribution of diet and occupational exposure to lung carcinogenesis is greater ${ }^{176}$. Is reasonable that most mechanisms described for its malignant transformation were elucidated using compounds present in cigarette smoke. Tobacco combustion produces at least 60 known carcinogens, most notably benzo (a) pyrene and 4- (methylnitrosamino) -1- (3-pyridyl) -1-butanone. Carcinogens present in cigarette smoke induce DDR, detoxification, and inflammation in lung epithelia associated with malignant transformation, apoptosis resistance, migration, and tumor growth 177-180. Furthermore, cell culture show proliferation in response to damage induced by molecules from cigarette smoke, as well as the production of interleukin 8 and the monocyte-attractant chemokine ${ }^{177-179}$. Accordingly, smokers eventually develop lung disorders characterized by constant inflammation such as chronic obstructive pulmonary disease, emphysema, and pulmonary fibrosis, which increase the risk of lung cancer 181-183. Patients diagnosed with lung cancer are older than 65 years in $60 \%$ of the cases but the incidence peaks by the age of $80{ }^{184}$. Young patients are generally diagnosed with adenocarcinomas, while squamous cell carcinoma is more common among the elderly ${ }^{185}$. The atypical adenomatous hyperplasia is considered the precursor of lung cancer and both coexist in $36 \%$ of cases ${ }^{186,187}$. Pulmonary hyperplasia shows molecular markers associated with cellular senescence such as the expression of the protein p16 ${ }^{188}$, and telomere shortening ${ }^{189}$. Notably, the accumulation of senescent cells and infiltration of immune cells are considered early events in their malignant transformation ${ }^{190,191}$ and $85 \%$ of the lesions emerge as non-small cell lung carcinoma ${ }^{7}$. Tumoral progression is accompanied by the silencing of E-cadherin ${ }^{192}$ and increased expression of Twist and Snail. The process of EMT is also associated with tumoral production of the immunosuppressive cytokines IL-10, TGF- $\beta$, the acquisition of mesenchymal histology, and an unfavorable prognosis ${ }^{193}$. Moreover, cells of the lung epithelium that undergo EMT are capable of expressing Oct, Nanog, CD44, and CD133 associated with cancer stem cells ${ }^{194}$, tumor initiation capacity, and high metastatic activity ${ }^{34,} 195$. Lung cancer progresses aggressively and survival for patients with localized disease is on average 13 months and 5 months for patients with metastases. The most common sites for metastasis are the nervous system, bones, and liver, but hepatic metastases have a poorer prognosis with only 3 months of survival ${ }^{196}$.

\section{Pancreatic cancer}

Pancreatic cancer is the seventh leading cause of death from neoplasia and the main risk factors are smoking, exposure to pesticides, obesity, and diabetes ${ }^{197}$. Smoking exposes the pancreas to polycyclic aromatic hydrocarbons and nitrosamines ${ }^{198}$. As a result of the chronic damage, the tissue overexpresses proinflammatory pathways involving the cyclooxygenases, lipoxygenases, and the production of TGF- $\beta$, TNF- $\alpha$, IL-1, and IL-6 ${ }^{198}$. Repeated proliferation and inflammation are contributing factors in the development of chronic or autoimmune pancreatitis ${ }^{199}$. In fact, smoking is associated with histological alterations in the pancreas, and the diagnosis of pancreatitis increases the risk for its malignant transformation ${ }^{200}$. The average age of diagnosis is 71 years, however, among smokers drops to 56 . Regarding histology, it has been observed that patients under 58 usually have endocrine tumors, whereas patients older than 67 are diagnosed with adenocarcinomas and mucinous tumors 201, 202. The precursor lesion of the pancreatic adenocarcinoma is the pancreatic intraductal neoplasia, on average, its diagnosis precedes 2 years the 
detection of the carcinoma ${ }^{203}$. Frequent findings before the malignant transformation of the pancreatic intraepithelial neoplasia are the expression of p16, short telomeres, the infiltration of immunological components, and changes in the stroma associated with inflammation ${ }^{203-205}$. Reactivation of the expression of the enzyme telomerase is common in pancreatic carcinoma ${ }^{206}$ and $95 \%$ display histology of ductal adenocarcinoma ${ }^{203}$. Then, these lesions progress with loss of differentiation of cells epithelial cells, luminal histology, and the negative regulation of E-cadherin ${ }^{207}$. The adoption of high tumor grade is accompanied by the presence of mesenchymal markers that predict poor prognosis ${ }^{208}$. Furthermore, the expression of Snaill and Zeb1 increase the number of cells with CD24 and CD44 related to the stem phenotype in pancreatic cancers ${ }^{209}$. In murine models of pancreatitis, cells that undergo EMT exhibit stem cell properties ${ }^{210}$, and cell cultures of murine pancreatic cancer cells confirmed that mesenchymal transcription factors are essential for the acquisition of the cancer stem cell phenotype and the formation of metastasis ${ }^{211,212}$. The global prognosis for patients diagnosed with pancreatic cancer remains unfavorable with a 5-year relative survival rate lower than $30 \%$ even when the disease is localized. Patients treated with first-line chemotherapy develop metastases rapidly ${ }^{213}$ and the relative survival rate at 5 years for metastatic disease is $4 \%$. On average, survival for patients with metastatic pancreatic cancer is 3 months and the most affected sites for the secondary masses are the peritoneum, the liver, the lungs, and distant lymph nodes ${ }^{214}$.

\section{Bladder cancer}

Bladder cancer is the thirteenth leading cause of death from neoplasia. Over half of cases are related to smoking however, in endemic areas of Schistosoma haematobium, infections play a more relevant role for bladder carcinogenesis 215, 216. Occupational exposure and obesity are also important factors, yet most knowledge of the process of malignant transformation in the bladder comes from studies in smokers or parasitosis. Smoking is associated with elevated levels of methylated polycyclic aromatic hydrocarbon metabolites and DNA damage. According to analysis, the epithelial cells of the bladder are exposed to the aromatic amines of tobacco; such as 2-naphthylamine, 4-aminobiphenyl, and benzidine that increase genetic damage and inflammation ${ }^{217,218}$. In the case of carcinogenesis due to schistosomiasis the presence of $\mathrm{N}$ nitroso compounds found in the urine of patients was related to mutagenesis ${ }^{219}$. In addition, chronic exposure to nitrosamines and immunological cells due to infection induces an environment prone to the malignant transformation of epithelial tissue in the bladder. Increased levels of TNF- $\alpha$, IL- 6 , and IL- $1 \alpha$ lead to proliferation, antagonism of apoptotic signals, angiogenesis, and remodeling of the extracellular matrix with the secretion of metalloproteinases 217,220 . In fact, the resulting chronic cystitis is a risk factor for the development of bladder cancer regardless of the etiology ${ }^{221}$. Transitional cell cancer is the predominant type of bladder cancer in developed countries, while in endemic regions of the parasite is more common the squamous cell carcinoma. On average, bladder cancer is diagnosed at age of 62 , but the highest frequency is presented at $89^{222}$. Of notice, patients under 40 years of age generally have small, low-grade tumors ${ }^{223}$. The precursor lesion of bladder cancer is the urothelial hyperplasia and in some cases within two years develops into neoplasia. As the atypia increases in the urothelial hyperplasia common changes in the molecular and cytological features are an enhanced expression of senescence biomarkers such as the p16 protein, telomere attrition, and the infiltration of leukocytes ${ }^{224-226}$. Histological progression to in situ carcinoma is accompanied by the reactivation of the enzyme telomerase ${ }^{227}$ and $90 \%$ of tumors corresponds to urothelial histology ${ }^{224}$. These carcinomas express E-cadherin but gradually evolve towards higher grades and loss the epithelial differentiation ${ }^{228}$. In contrast markers of mesenchymal proteins such as Twist and vimentin increase and are associated with metastasis ${ }^{229}$. The process of EMT in bladder tumor samples correlates with the expression of CD44, CD133, BMI1, YAP1, hence with the presence of cancer stem cells but also with the number of metastasis ${ }^{230-233}$. The prognosis for patients diagnosed with localized disease is favorable, with a 5-year relative survival rate greater than $95 \%$; however, in patients with metastatic disease, progression-free survival is 7 months despite treatment. The tissues most affected by metastases are bone, brain, liver, and lungs ${ }^{233,234}$. 


\section{Liver Cancer}

Liver cancer is the fourth leading cause of death from malignant tumors; over $80 \%$ of cases are induced by viruses or flatworms. The most important are infections with the hepatitis $\mathrm{B}$ virus, the hepatitis $\mathrm{C}$ virus, or with the flukes of the species Clonorchis, Opisthorchis, and Fasciola. Other risk factors associated with the development of hepatocarcinoma are hemochromatosis, exposure to chemicals or drugs, smoking, alcoholism, obesity, metabolic syndrome, and diabetes ${ }^{235,236}$. The combined effect of chronic infection, chemical exposure, or metabolic disorders causes cellular stress and oxidative microenvironment that enhances proliferation and inflammation in response to tissue damage in the liver. The production of proinflammatory cytokines such as IL- 6 , TNF- $\alpha$, the activity of the transcription factors NF-kB and STAT- 3 mediate liver and immune system responses to fight infection and to activate the mechanisms of repair ${ }^{237}$. In the case of ethanol, its metabolization produces acetaldehyde, which is very toxic and carcinogenic. As expected, chronic alcohol use causes liver hyperproliferation and transformation ${ }^{238}$. Frequent exposure to risk factors causes histological changes in the liver associated with hepatitis, fatty liver disease, or cirrhosis, which in turn precede the development of hepatocarcinoma ${ }^{239}$. Liver cancer is diagnosed after 45 years of age in $95 \%$ of the cases, on average at 63 but the highest peak is reached at 83 . At the time of diagnosis, $80 \%$ of liver neoplasms exhibit the histological subtype of hepatocellular carcinoma, the rest correspond to intrahepatic cholangiocarcinoma and less common varieties ${ }^{240}$. The continuous proliferation in response to infection or toxic chemical substances, generates a progressive telomere shortening ${ }^{241}$, activation of the INK4a locus, and accumulation of senescent cells expressing markers such as the $\beta$-galactosidase and the heterochromatin foci 242. Those molecular changes, in turn, lead to cytological or architectural atypia known as high dysplastic nodule grade. In half of the cases, this lesion then progresses into hepatocarcinoma within a year ${ }^{243}$. The malignant transformation of the high-grade dysplastic nodule is often accompanied by infiltration of the immune system and cytokine production ${ }^{244}$ and at this stage in hepatocarcinogenesis telomerase is reactivated 245 and p16 protein is silenced ${ }^{246}$. Up to $85 \%$ of diagnosed liver neoplasms are well-differentiated tumors classified histologically as hepatocellular carcinoma ${ }^{247}$. Upon progression to a high histological grade is accompanied by the loss of normal morphological characteristics, including the E-cadherin whereas the transcription factors associated with EMT such as Snail, Slug, and Twist are increased ${ }^{248,249}$. The expression of mesenchymal proteins correlates with the detection of circulating tumor cells, metastases, and a more aggressive course of the disease ${ }^{250,251}$. EMT induced by IL-6 derived from macrophages that infiltrate the liver tumor promotes the gain of markers of cancer stem cells, invasion, and metastasis. These cells, which possess the markers CD44 and CD133, predict drug resistance, tumor recurrence, and poor survival even after successful surgery ${ }^{252,253}$. Regarding the 5-year relative survival rate, for patients with localized disease is $30 \%$ whereas those diagnosed in stage IV is $3 \%$. Metastasis mostly affects the bones, lungs, and brain, this last one is associated with the worst prognosis with an average survival of only 5 months ${ }^{254}$. In general, cytotoxic therapy does not provide a significant survival benefit in patients with disseminated disease 255,256 .

Cervical cancer

Cervical cancer is the fourth leading cause of death from cancer. Lifestyle factors associated with an increased risk for developing cervical cancer are smoking, human papillomavirus (HPV) infections, herpesvirus, and hormone therapy. The main etiological agent of cervical cancer is HPV since $70 \%$ of cases are associated with infection ${ }^{257}$. Exposure of human cervical epithelial cells to the virus induces their proliferation, the activation of COX enzymes, the production of inflammatory prostaglandins and Il- $1 \alpha$, IL-6, and the EGF ${ }^{258}$. Persistent infection with HPV leads to low-grade squamous intraepithelial lesions that eventually progress to invasive cervical cancer. Other viruses, bacteria, protozoa, foreign bodies, trauma, or chemicals are also capable of inducing alterations in the epithelium that cause chronic inflammation and the remodeling of the tissue associated with pelvic inflammatory diseases that can also progress to carcinomas ${ }^{259}$. On average, the age of diagnosis is 50 years, and $80 \%$ of the cases occur in the range of 35 to 54 years. Up to $80 \%$ of the patients present the histological subtype of squamous cell carcinoma and the rest of the cases correspond mainly to adenosquamous carcinoma ${ }^{260}$. Cervical intraepithelial neoplasia is considered the precursor to 
cervical cancer ${ }^{261}$. It is estimated that its malignant transformation process takes 20 years, but when intraepithelial neoplasia is associated with HPV-16 infection, progression takes only 10 years 262 . Intraepithelial neoplasms present overexpression of the protein p16 ${ }^{263}$, short telomeres, and lymphocyte infiltration along with increased atypia ${ }^{264}$. In contrast, carcinomas reduce the expression of senescence, and telomerase activity is recovered ${ }^{265,266}$. The progression of cervical cancer involves the loss of the epithelial phenotype and the gain of expression of mesenchymal markers. Furthermore, in cervical cancer, the expression of vimentin and EMT markers positively correlates with the grade of invasion, higher tumoral grade $^{267}$, the expression of the mesenchymal transcription factors Snai1, Snai2, Twist1, the cancer stem cells markers CD133, Oct4, Sox2, Nanog, and with the number of metastasis ${ }^{268-270}$. The prognosis of patients with localized disease is favorable, with a 5-year relative survival rate greater than $90 \%$; however, in patients with metastatic disease, progression-free survival is 11 months despite treatment. The most common sites of metastasis are bones, lungs, liver, and lymph nodes. However, hepatic metastases worsen the prognosis with an average survival of 6 months ${ }^{271}$.

\section{References}

1. Ahmad, A.; Banerjee, S.; Wang, Z.; Kong, D.; Majumdar, A. P.; Sarkar, F. H. Aging and inflammation: etiological culprits of cancer. Current aging science, 2009, 2 (3), 174-86.

2. Méndez-López, L. F.; Zapata-Benavides, P.; Zavala-Pompa, A.; Aguado-Barrera, M. E.; Pacheco-Calleros, J.; Rodríguez-Padilla, C.; Cerda-Flores, R. M.; Cortés-Gutiérrez, E. I.; Dávila-Rodríguez, M. I. Immunohistochemical analysis of prostate apoptosis response-4 (Par-4) in Mexican women with breast cancer: a preliminary study. Archives of medical research 2010, 41 (4), 261-268.

3. Méndez-López, L. F.; Zavala-Pompa, A.; Cortés-Gutiérrez, E. I.; Cerda-Flores, R. M.; Davila-Rodriguez, M. I. Leptin receptor expression during the progression of endometrial carcinoma is correlated with estrogen and progesterone receptors. Archives of medical science 2017, 13 (1), 228.

4. Cserni, G. Tumour histological grade may progress between primary and recurrent invasive mammary carcinoma. Journal of clinical pathology, 2002, 55 (4), 293-7.

5. Micalizzi, D. S.; Farabaugh, S. M.; Ford, H. L. Epithelial-mesenchymal transition in cancer: parallels between normal development and tumor progression. Journal of mammary gland biology and neoplasia 2010, 15 (2), 117-34.

6. Méndez-López, L. F. On the Origin of Carcinoma. Preprints 2021, 01 (05), 1-32.

7. Siegel, R. L.; Miller, K. D.; Jemal, A. Cancer statistics, 2016. CA: A Cancer journal for clinicians 2016, 66 (1), 7-30.

8. Tyler, S. J. Epithelium, the primary building block for metazoan complexity. Integrative and comparative biology 2003, 43 (1), 55-63.

9. Chen, Y.; Zhang, L.; Liu, W.; Liu, X. Prognostic significance of the tumor-stroma ratio in epithelial ovarian cancer. BioMed research international 2015.

10. Sarrió, D.; Rodriguez-Pinilla, S. M.; Hardisson, D.; Cano, A.; Moreno-Bueno, G.; Palacios, J. Epithelial-mesenchymal transition in breast cancer relates to the basal-like phenotype. Cancer research 2008, 68 (4), 989-997.

11. Finak, G.; Bertos, N.; Pepin, F.; Sadekova, S.; Souleimanova, M.; Zhao, H.; Chen, H.; Omeroglu, G.; Meterissian, S.; Omeroglu, A. Stromal gene expression predicts clinical outcome in breast cancer. Nature medicine 2008, 14 (5), 518-527.

12. Ugnat, A.; Xie, L.; Morriss, J.; Semenciw, R.; Mao, Y. Survival of women with breast cancer in Ottawa, Canada: variation with age, stage, histology, grade and treatment. British Journal of cancer 2004, 90 (6), 1138.

13. Anand, P.; Kunnumakkara, A. B.; Sundaram, C.; Harikumar, K. B.; Tharakan, S. T.; Lai, O. S.; Sung, B.; Aggarwal, B. B. Cancer is a preventable disease that requires major lifestyle changes. Pharmaceutical research 2008, 25 (9), 2097-116.

14. Friedenreich, C.; Bryant, H.; Alexander, F.; Hugh, J.; Danyluk, J.; Page, D. Risk factors for benign proliferative breast disease. International journal of epidemiology 2000 29(4), 637-644.

15. Djuric, Z.; Edwards, A.; Madan, S.; Darga, L.; Ren, J.; Blake, C.; Koletsky, M.; Heilbrun, L. K. Obesity is associated with atypia in breast ductal lavage of women with proliferative breast disease. Cancer epidemiology 2009, 33 (3-4), 242-248.

16. Eyre, H.; Kahn, R.; Robertson, R. M.; Clark, N. G.; Doyle, C.; Hong, Y.; Gansler, T.; Glynn, T.; Smith, R. A.; Taubert, K.; Thun, M. J. Preventing cancer, cardiovascular disease, and diabetes: a common agenda for the American Cancer Society. Stroke 2004, 35 (8), 1999-2010.

17. Howell, A.; Anderson, A. S.; Clarke, R. B.; Duffy, S. W.; Evans, D. G.; Garcia-Closas, M.; Gescher A. J. Risk determination and prevention of breast cancer. Breast Cancer Research 2014, 16(5), 1-19.

18. Calle, E. E.; Kaaks, R. Overweight, obesity and cancer: epidemiological evidence and proposed mechanisms. Nature Reviews Cancer 2004, 4 (8), 579-591.

19. Scaling, A. L.; Prossnitz, E. R.; Hathaway, H. J. GPER mediates estrogen-induced signaling and proliferation in human breast epithelial cells and normal and malignant breast. Hormones and Cancer 2014, 5 (3), 146-160.

20. Bendrik, C.; Dabrosin, C. Estradiol increases IL-8 secretion of normal human breast tissue and breast cancer in vivo. The Journal of Immunology 2009, $182(1), 371-378$. 
21. Speirs, V.; Kerin, M.; Walton, D.; Newton, C.; Desai, S.; Atkin, S. Direct activation of oestrogen receptor- $\alpha$ by interleukin-6 in primary cultures of breast cancer epithelial cells. British journal of cancer 2000, 82 (7), 1312.

22. Ando, S.; Catalano, S. The multifactorial role of leptin in driving the breast cancer microenvironment. Nature Reviews Endocrinology $20128(5), 263$.

23. Donnelly, P.; Baker, K.; Carney, J.; O'Fallon, W. In Benign breast lesions and subsequent breast carcinoma in Rochester, Minnesota. Mayo Clinic proceedings, 1975; 650-656.

24. Lambe, M.; Johansson, A. L.; Altman, D.; Eloranta, S. J. Mastitis and the risk of breast cancer. Epidemiology 2009, 747-751.

25. Dupont, W. D.; Parl, F. F.; Hartmann, W. H.; Brinton, L. A.; Winfield, A. C.; Worrell, J. A.; Schuyler, P. A.; Plummer, W. D. Breast cancer risk associated with proliferative breast disease and atypical hyperplasia. Cancer 1993, 71 (4), 1258-1265.

26. Benz, C. C. Impact of aging on the biology of breast cancer. Critical reviews in oncology/hematology 2008, 66(1), 65-74.

27. Malhotra, G. K.; Zhao, X.; Band, H.; Band, V. Histological, molecular and functional subtypes of breast cancers. Cancer biology and therapy 2010, $10(10), 955-960$.

28. Radisky, D. C.; Santisteban, M.; Berman, H. K.; Gauthier, M. L.; Frost, M. H.; Reynolds, C. A.; Vierkant, R. A.; Pankratz, V. S.; Visscher, D. W.; Tlsty, T. D. p16INK4a expression and breast cancer risk in women with atypical hyperplasia. Cancer prevention research, 2011, 4 (12), 1953-1960.

29. DeNardo, D. G.; Coussens, L. M. Inflammation and breast cancer. Balancing immune response: crosstalk between adaptive and innate immune cells during breast cancer progression. Breast Cancer Research 2007, 9 (4), 1.

30. Pare, R.; Soon, P. S.; Shah, A.; Lee, C. S. Differential expression of senescence tumour markers and its implications on survival outcomes of breast cancer patients. PloS one 2019, 14 (4).

31. Umbricht, C. B.; Sherman, M. E.; Dome, J.; Carey, L.; Marks, J.; Kim, N.; Sukumar, S. J. Telomerase activity in ductal carcinoma in situ and invasive breast cancer. Oncogene 1999, 18 (22), 3407-3414.

32. Meeker, A. K.; Hicks, J. L.; Gabrielson, E.; Strauss, W. M.; De Marzo, A. M.; Argani, P. J. Telomere shortening occurs in subsets of normal breast epithelium as well as in situ and invasive carcinoma. The American journal of pathology 2004, 164 (3), 925-935.

33. Younis, L. K.; El Sakka, H.; Haque, I. The prognostic value of E-cadherin expression in breast cancer. Journal of health sciences 2010, 1 (1).

34. Chen, Y.C.; Hsu, H.S.; Chen, Y.W.; Tsai, T. H.; How, C. K.; Wang, C. Y.; Hung, S.C.; Chang, Y.-L.; Tsai, M.L.; Lee, Y. Oct-4 expression maintained cancer stem-like properties in lung cancer-derived CD133-positive cells. PloS one 2008, 3 (7).

35. Dongre, A.; Rashidian, M.; Reinhardt, F.; Bagnato, A.; Keckesova, Z.; Ploegh, H. L.; Weinberg, R. A. Epithelial-to-mesenchymal transition contributes to immunosuppression in breast carcinomas. Cancer research, 2017, 77 (15) 3982-3989.

36. Lakhtakia, R.; Aljarrah, A.; Furrukh, M.; Ganguly, S. Epithelial mesenchymal transition (EMT) in metastatic breast Cancer in Omani women. Cancer Microenvironment 2017, 10 (1-3), 25-37.

37. Kassam, F.; Enright, K.; Dent, R.; Dranitsaris, G.; Myers, J.; Flynn, C.; Fralick, M.; Kumar, R.; Clemons, M. Survival outcomes for patients with metastatic triple-negative breast cancer: implications for clinical practice and trial design. Clinical breast cancer 2009,9 (1), 29-33.

38. Minn, A. J.; Kang, Y.; Serganova, I.; Gupta, G. P.; Giri, D. D.; Doubrovin, M.; Ponomarev, V.; Gerald, W. L.; Blasberg, R.; Massagué, J. Distinct organ-specific metastatic potential of individual breast cancer cells and primary tumors. The Journal of clinical investigation 2005, 115 (1), 44-55.

39. Patanaphan, V.; Salazar, O. M.; Risco, R. Breast cancer: metastatic patterns and their prognosis. Southern medical journal 1988, 81 (9), 1109-1112.

40. Sementchenko, V. I.; Watson, D. K. Ets target genes: past, present and future. Oncogene 2000, 19 (55), 6533-48.

41. Hollenhorst, P. C.; Jones, D. A.; Graves, B. J. Expression profiles frame the promoter specificity dilemma of the ETS family of transcription factors. Nucleic Acids Research 2004, 32 (18), 5693-702.

42. Donnison, M.; Beaton, A.; Davey, H. W.; Broadhurst, R.; L'Huillier, P.; Pfeffer, P. L. Loss of the extraembryonic ectoderm in Elf5 mutants leads to defects in embryonic patterning. Development 2005, 132 (10), 2299-308.

43. Chen, Z.; Trotman, L. C.; Shaffer, D.; Lin, H. K.; Dotan, Z. A.; Niki, M.; Koutcher, J. A.; Scher, H. I.; Ludwig, T.; Gerald, W.; Cordon-Cardo, C.; Pandolfi, P. Crucial role of p53-dependent cellular senescence in suppression of Pten deficient tumorigenesis. Nature 2005, 436 (7051), 725-30.

44. Graham, M. K.; Meeker, A. J. Telomeres and telomerase in prostate cancer development and therapy. Nature Reviews Urology 2017, $14(10), 607$.

45. Burma, S.; Chen, B. P.; Murphy, M.; Kurimasa, A.; Chen, D. J. ATM phosphorylates histone H2AX in response to DNA doublestrand breaks. Journal of Biological Chemistry 2001, 276 (45), 42462-7.

46. Herbig, U.; Jobling, W. A.; Chen, B. P.; Chen, D. J.; Sedivy, J. M. Telomere shortening triggers senescence of human cells through a pathway involving ATM, p53, and p21(CIP1), but not p16(INK4a). Molecular cell 2004, 14 (4), 501-13.

47. Krishnamurthy, J.; Torrice, C.; Ramsey, M. R.; Kovalev, G. I.; Al-Regaiey, K.; Su, L.; Sharpless, N. E. Ink4a/Arf expression is a biomarker of aging. The Journal of clinical investigation 2004, 114 (9), 1299-307.

48. Bracken, A. P.; Kleine-Kohlbrecher, D.; Dietrich, N.; Pasini, D.; Gargiulo, G.; Beekman, C.; Theilgaard-Mönch, K.; Minucci, S.; Porse, B. T.; Marine, J.C. The Polycomb group proteins bind throughout the INK4A-ARF locus and are disassociated in senescent cells. Genes \& development 2007, 21 (5), 525-530.

49. Sparmann, A.; van Lohuizen, M. Polycomb silencers control cell fate, development and cancer. Nature Reviews Cancer 2006, 6 (11), 846-56.

50. Chandler, C.; Liu, T.; Buckanovich, R.; Coffman, L. The double edge sword of fibrosis in cancer. Translational Research 2019. 
51. Bartoschek, M.; Oskolkov, N.; Bocci, M.; Lövrot, J.; Larsson, C.; Sommarin, M.; Madsen, C. D.; Lindgren, D.; Pekar, G.; Karlsson, G. Spatially and functionally distinct subclasses of breast cancer-associated fibroblasts revealed by single cell RNA sequencing. Nature communications 2018, 9 (1), 5150.

52. Ray, T., Shah, A., Bulla, G. A., Ray, P. S. Gatekeeper transcription factors regulate switch between lineage preservation and cell plasticity. bioRxiv 2020.

53. Koch, C. M., Suschek, C. V., Lin, Q., Bork, S., Goergens, M., Joussen, S., Wagner, W. Specific age-associated DNA methylation changes in human dermal fibroblasts. PloS one 2011, 6(2), e16679.

54. Selman, M., Pardo, A., Kaminski, N. Idiopathic pulmonary fibrosis: aberrant recapitulation of developmental programs? PLoS Med, 2008, 5(3), e62.

55. Xie, T., Liang, J., Liu, N., Huan, C., Noble, P. W. Transcription factor TBX4 regulates myofibroblast accumulation and lung fibrosis. The Journal of clinical investigation 2016, 126(8), 3063-3079.

56. Lai, P. L., Lin, H., Chen, S. F., Lu, J. Efficient generation of chemically induced mesenchymal stem cells from human dermal fibroblasts. Scientific reports 2017, 7(1), 1-13.

57. Stampfer, M. R.; LaBarge, M. A.; Garbe, J. C. An integrated human mammary epithelial cell culture system for studying carcinogenesis and aging. In Cell and Molecular Biology of Breast Cancer, Springer: 2013; pp 323-361.

58. de Lange, T., Cell biology. Telomere capping one strand fits all. Science 2001, 292 (5519), 1075-6

59. Karlseder, J.; Smogorzewska, A.; de Lange, T. Senescence induced by altered telomere state, not telomere loss. Science 2002,295 (5564), 2446-9.

60. von Zglinicki, T.; Saretzki, G.; Ladhoff, J.; d'Adda di Fagagna, F.; Jackson, S. P. Human cell senescence as a DNA damage response. Mechanisms of ageing and development 2005, 126 (1), 111-7.

61. Rogakou, E. P.; Pilch, D. R.; Orr, A. H.; Ivanova, V. S.; Bonner, W. M. DNA double-stranded breaks induce histone H2AX phosphorylation on serine 139. Journal of biological chemistry 1998, 273 (10), 5858-68.

62. el-Deiry, W. S.; Kern, S. E.; Pietenpol, J. A.; Kinzler, K. W. Vogelstein, B. Definition of a consensus binding site for p53. Nature genetics 1992, 1 (1), 45-9.

63. de Stanchina, E.; Querido, E.; Narita, M.; Davuluri, R. V.; Pandolfi, P. P.; Ferbeyre, G.; Lowe, S. W. PML is a direct p53 target that modulates p53 effector functions. Molecular cell 2004, 13 (4), 523-35.

64. Sau, A., Cabrita, M. A., Pratt, M. C. NF- $\mathrm{kB}$ at the Crossroads of Normal Mammary Gland Biology and the Pathogenesis and Prevention of BRCA1-Mutated Breast Cancer. Cancer Prevention Research 2018, 11(2), 69-80.

65. Coppe, J. P.; Patil, C. K.; Rodier, F.; Sun, Y.; Munoz, D. P.; Goldstein, J.; Nelson, P. S.; Desprez, P. Y.; Campisi, J. Senescenceassociated secretory phenotypes reveal cell-nonautonomous functions of oncogenic RAS and the p53 tumor suppressor. PLoS Biol 2008, 6 (12), 2853-68.

66. Rovillain, E.; Mansfield, L.; Caetano, C.; Alvarez-Fernandez, M.; Caballero, O. L.; Medema, R. H.; Hummerich, H.; Jat, P. Activation of nuclear factor-kappa B signalling promotes cellular senescence. Oncogene 2011, 30 (20), 2356.

67. Ansieau, S.; Morel, A.; Hinkal, G.; Bastid, J.; Puisieux, A. TWISTing an embryonic transcription factor into an oncoprotein. Oncogene 2010, 29 (22), 3173.

68. Suarez-Carmona, M.; Lesage, J.; Cataldo, D.; Gilles, C. EMT and inflammation: inseparable actors of cancer progression. Molecular oncology 2017, 11 (7), 805-823.

69. Li, H.; Lin, X. Positive and negative signaling components involved in TNF alpha-induced NF-kappa B activation. Cytokine 2008, 41 (1), 1-8.

70. Wang, L.; Walia, B.; Evans, J.; Gewirtz, A. T.; Merlin, D.; Sitaraman, S. V. IL-6 induces NF-kappa B activation in the intestinal epithelia. Journal of Immunology 2003, 171 (6), 3194-201.

71. Freudlsperger, C.; Bian, Y.; Contag Wise, S.; Burnett, J.; Coupar, J.; Yang, X.; Chen, Z.; Van Waes, C. TGF-beta and NF-kappaB signal pathway cross-talk is mediated through TAK1 and SMAD7 in a subset of head and neck cancers. Oncogene 2013, 32 (12), 154959 .

72. Mani, S. A.; Yang, J.; Brooks, M.; Schwaninger, G.; Zhou, A.; Miura, N.; Kutok, J. L.; Hartwell, K.; Richardson, A. L.; Weinberg, R. A. Mesenchyme Forkhead 1 (FOXC2) plays a key role in metastasis and is associated with aggressive basal-like breast cancers. Proceedings of the National Academy of Sciences 2007, 104 (24), 10069-74.

73. Chua, H. L.; Bhat-Nakshatri, P.; Clare, S. E.; Morimiya, A.; Badve, S.; Nakshatri, H. NF-kappaB represses E-cadherin expression and enhances epithelial to mesenchymal transition of mammary epithelial cells: potential involvement of ZEB-1 and ZEB-2. Oncogene 2007, $26(5), 711-24$.

74. Dave, N.; Guaita-Esteruelas, S.; Gutarra, S.; Frias, A.; Beltran, M.; Peiro, S.; de Herreros, A. G. Functional cooperation between Snaill and twist in the regulation of ZEB1 expression during epithelial to mesenchymal transition. Journal of Biological Chemistry 2011, 286 (14), 12024-32.

75. Mani, S. A.; Guo, W.; Liao, M. J.; Eaton, E. N.; Ayyanan, A.; Zhou, A. Y.; Brooks, M.; Reinhard, F.; Zhang, C. C.; Shipitsin, M.; Campbell, L. L.; Polyak, K.; Brisken, C.; Yang, J.; Weinberg, R. A. The epithelial-mesenchymal transition generates cells with properties of stem cells. Cell 2008, 133 (4), 704-15.

76. Xie, G.; Ji, A.; Yuan, Q.; Jin, Z.; Yuan, Y.; Ren, C.; Guo, Z.; Yao, Q.; Yang, K.; Lin, X. J. Tumour-initiating capacity is independent of epithelial-mesenchymal transition status in breast cancer cell lines. British journal of cancer 2014, 110 (10), 2514.

77. Floor, S.; van Staveren, W. C.; Larsimont, D.; Dumont, J. E.; Maenhaut, C. Cancer cells in epithelial-to-mesenchymal transition and tumor-propagating-cancer stem cells: distinct, overlapping or same populations. Oncogene 2011, 30 (46), 4609-21. 
78. Li, Q. Q.; Xu, J. D.; Wang, W. J.; Cao, X. X.; Chen, Q.; Tang, F.; Chen, Z. Q.; Liu, X. P.; Xu, Z. D. Twist1-mediated adriamycininduced epithelial-mesenchymal transition relates to multidrug resistance and invasive potential in breast cancer cells. Clinical Cancer Research 2009, 15 (8), 2657-65.

79. Hiscox, S.; Jiang, W. G.; Obermeier, K.; Taylor, K.; Morgan, L.; Burmi, R.; Barrow, D.; Nicholson, R. I. Tamoxifen resistance in MCF7 cells promotes EMT-like behaviour and involves modulation of beta-catenin phosphorylation. International journal of cancer 2006, 118(2), 290-301.

80. Terry, S.; Savagner, P.; Ortiz-Cuaran, S.; Mahjoubi, L.; Saintigny, P.; Thiery, J. P.; Chouaib, S. New insights into the role of EMT in tumor immune escape. Molecular oncology 2017, 11 (7), 824-846.

81. Wang, E. Cancer systems biology. CRC Press/Taylor \& Francis, 2010; 419.

82. Peñalosa-Ruiz, G.; Bright, A. R.; Mulder, K. W.; Veenstra, G. The interplay of chromatin and transcription factors during cell fate transitions in development and reprogramming. Biochimica et Biophysica Acta (BBA)-Gene Regulatory Mechanism 2019,1862 (9), 194407.

83. Huang, S.; Kauffman, S. A. Complex GRN complex Gene Complex GRN Regulatory Networks-from Structure to Biological Observables: Cell Fate Determination Gene regulation, cell fate determination. Computational Complexity: Theory, Techniques, and Applications 2012, 527-560.

84. Huang, S., Eichler, G., Bar-Yam, Y., Ingber, D. E. Cell fates as high-dimensional attractor states of a complex gene regulatory network. Physical review letters 2005, 94(12), 128701.

85. Huang, S.; Ingber, D. E. Shape-dependent control of cell growth, differentiation, and apoptosis: switching between attractors in cell regulatory networks. Experimental cell research 2000, 261(1), 91-103.

86. Turdo, A., Veschi, V., Gaggianesi, M., Chinnici, A., Bianca, P., Todaro, M., Stassi, G. Meeting the challenge of targeting cancer stem cells. Frontiers in cell and developmental biology 2019, 7, 16.

87. Wang, R. S., Saadatpour, A., Albert, R. Boolean modeling in systems biology: an overview of methodology and applications. Physical biology 2012, 9(5), 055001.

88. Méndez-López, L. F.; Davila-Velderrain, J.; Domínguez-Hüttinger, E.; Enríquez-Olguín, C.; Martínez-García, J. C.; Alvarez-Buylla, E. R. Gene regulatory network underlying the immortalization of epithelial cells. BMC systems biology 2017, 11 (1), 24.

89. Ortiz-Montero, P.; Londoño-Vallejo, A.; Vernot, J. P. Signaling, Senescence-associated IL-6 and IL-8 cytokines induce a self-and cross-reinforced senescence/inflammatory milieu strengthening tumorigenic capabilities in the MCF-7 breast cancer cell line. Cell Communication and Signaling 2017, 15 (1), 17.

90. Waters, D. W.; Blokland, K. E.; Pathinayake, P. S.; Burgess, J. K.; Mutsaers, S. E.; Prele, C. M.; Schuliga, M.; Grainge, C. L.; Knight, D. A. Fibroblast senescence in the pathology of idiopathic pulmonary fibrosis. American Journal of Physiology-Lung Cellular and Molecular Physiology 2018, 315(2), L162-L172.

91. Willis, B. C.; duBois, R. M.; Borok, Z. Epithelial origin of myofibroblasts during fibrosis in the lung. Proceedings of the American Thoracic Society 2006, 3 (4), 377-382.

92. Lu, W., Kang, Y. Epithelial-mesenchymal plasticity in cancer progression and metastasis. Developmental cell 2019, 49(3), 361-374.

93. Li, Y., Zhao, H., Huang, X., Zhou, B. Embryonic senescent cells re-enter cell cycle and contribute to tissues after birth. Cell research 2018, 28(7), 775-778.

94. Cruickshanks, H. A.; McBryan, T.; Nelson, D. M.; VanderKraats, N. D.; Shah, P. P.; van Tuyn, J.; Rai, T. S.; Brock, C.; Donahue, G.; Dunican, D. S. Senescent cells harbour features of the cancer epigenome. Nature cell biology 2013.

95. Casanova, J. Stemness as a cell default state. EMBO reports 2012, 13 (5), 396-7.

96. Becker-Weimann, S.; Xiong, G.; Furuta, S.; Han, J.; Kuhn, I.; Akavia, U. D.; Pe'er, D.; Bissell, M. J.; Xu, R. NF-kB disrupts tissue polarity in 3D by preventing integration of microenvironmental signals. Oncotarget 2013, 4 (11), 2010.

97. Oltean, S.; Febbo, P. G.; Garcia-Blanco, M. Dunning rat prostate adenocarcinomas and alternative splicing reporters: powerful tools to study epithelial plasticity in prostate tumors in vivo. Clinical \& experimental metastasis 2008, 25 (6), 611-619.

98. Chao, Y. L.; Shepard, C. R.; Wells, A. Breast carcinoma cells reexpress E-cadherin during mesenchymal to epithelial reverting transition. Molecular cancer 2010, 9 (1), 179.

99. Chaffer, C. L.; Brennan, J. P.; Slavin, J. L.; Blick, T.; Thompson, E. W.; Williams, E. Mesenchymal-to-epithelial transition facilitates bladder cancer metastasis: role of fibroblast growth factor receptor-2. Cancer research 2006, 66 (23), 11271-11278.

100. Yao, D., Dai, C., Peng, S. Mechanism of the mesenchymal-epithelial transition and its relationship with metastatic tumor formation. Molecular cancer research 2011,9 (12), 1608-1620.

101. Yuan, S.; Norgard, R. J.; Stanger, B. Z. Cellular plasticity in cancer. Cancer discovery 2019, 9 (7), 837-851.

102. Anderson, W. F.; Pfeiffer, R. M.; Dores, G. M.; Sherman, M. E. Comparison of age distribution patterns for different histopathologic types of breast carcinoma. Cancer Epidemiology and Prevention Biomarkers 2006, 15 (10), 1899-1905.

103. Al-Hajj, M.; Wicha, M. S.; Benito-Hernandez, A.; Morrison, S. J.; Clarke, M. F. Prospective identification of tumorigenic breast cancer cells. Proceedings of the National Academy of Sciences 2003, 100 (7), 3983-3988.

104. Beavis, A. L.; Smith, A. J. B.; Fader, A. N. Lifestyle changes and the risk of developing endometrial and ovarian cancers: opportunities for prevention and management. International journal of women's health, 2016, 8, 151.

105. Ramos-Nino, M. E. The role of chronic inflammation in obesity-associated cancers. International Scholarly Research Notices 2013, 697521.

106. Punyadeera, C.; Dunselman, G.; Marbaix, E.; Kamps, R.; Galant, C.; Nap, A.; de Goeij, A.; Ederveen, A.; Groothuis, P. Triphasic pattern in the ex vivo response of human proliferative phase endometrium to oestrogens. The Journal of steroid biochemistry and molecular biology 2004, 92 (3), 175-185. 
107. Rutanen, E. M. Insulin-like growth factors in endometrial function. Gynecological Endocrinology 1998, 12 (6), $399-406$.

108. Villavicencio, A.; Aguilar, G.; Argüello, G.; Dünner, C.; Gabler, F.; Soto, E.; Gaete, F.; Peñaloza, P.; Celis, M.; Rojas, C. The effect of overweight and obesity on proliferation and activation of AKT and ERK in human endometria. Gynecologic oncology 2010,117 (1), 96-102.

109. Patsner, B. J. Endometrial cancer in women 45 years of age or younger. European journal of gynaecological oncology, 2000,21 (3), 249-250.

110. Nevadunsky, N. S.; Van Arsdale, A.; Strickler, H. D.; Moadel, A.; Kaur, G.; Levitt, J.; Girda, E.; Goldfinger, M.; Goldberg, G. L.; Einstein, M. H. Obesity and age at diagnosis of endometrial cancer. Obstetrics and Gynecology 2014, 124 (2), 300-306.

111. Hisamatsu, K.; Noguchi, K.; Tomita, H.; Muto, A.; Yamada, N.; Kobayashi, K.; Hirata, A.; Kanayama, T.; Niwa, A.; Ishida, K. J. Distinctive crypt shape in a sessile serrated adenoma/polyp: Distribution of Ki67-, p16INK4a-, WNT5A-positive cells and intraepithelial lymphocytes. Oncology reports 2017, 38 (2), 775-784.

112. Hu, H.-L.; Bai, H.-S.; Pan, H.-X. Correlation between TAMs and proliferation and invasion of type I endometrial carcinoma. Asian Pacific journal of tropical medicine 2015, 8 (8), 643-650.

113. Mingels, M. J.; Masadah, R.; Geels, Y. P.; Otte-Höller, I.; de Kievit, I. M.; van der Laak, J. A.; van Ham, M. A.; Bulten, J.; Massuger, L. F. High prevalence of atypical hyperplasia in the endometrium of patients with epithelial ovarian cancer. American journal of clinical pathology 2014, 142(2), 213-221.

114. Jarboe, E. A.; Mutter, G. L. Endometrial intraepithelial neoplasia, Seminars in diagnostic pathology, Elsevier: 2010; pp 215-225.

115. Danescu, A.; Herrero Gonzalez, S.; Di Cristofano, A.; Mai, S.; Hombach-Klonisch, S. J. Three-dimensional nuclear telomere architecture changes during endometrial carcinoma development. Genes, Chromosomes and Cancer 2013, 5 2(8), 716-732.

116. Saito, T.; Schneider, A.; Martel, N.; Mizumoto, H.; Bulgay-Moerschel, M.; Kudo, R.; Nakazawa, H. Proliferation-associated regulation of telomerase activity in human endometrium and its potential implication in early cancer diagnosis. Biochemical and biophysical research communications 1997, 231 (3), 610-614.

117. Maida, Y.; Kyo, S.; Kanaya, T.; Wang, Z.; Tanaka, M.; Yatabe, N.; Nakamura, M.; Inoue, M. Is the telomerase assay useful for screening of endometrial lesions? International journal of cancer 2002, 100 (6), 714-718.

118. Bartosch, C.; Monteiro-Reis, S.; Vieira, R.; Pereira, A.; Rodrigues, M.; Jerónimo, C.; Lopes, J. M. Endometrial Endometrioid Carcinoma Metastases Show Decreased ER-Alpha and PR-A Expression Compared to Matched Primary Tumors. PloS one 2015, 10 (8), e0134969.

119. Nesina, I.; Iurchenko, N.; Buchynska, L. Markers of the epithelial-mesenchymal transition in cells of endometrial carcinoma. Experimental oncology 2018.

120. Nakamura, M.; Zhang, X.; Mizumoto, Y.; Maida, Y.; Bono, Y.; Takakura, M.; Kyo, S. Molecular characterization of CD133+ cancer stem-like cells in endometrial cancer. International journal of oncology 2014, 44 (3), 669-677.

121. Kusunoki, S.; Kato, K.; Tabu, K.; Inagaki, T.; Okabe, H.; Kaneda, H.; Suga, S.; Terao, Y.; Taga, T.; Takeda, S. J. The inhibitory effect of salinomycin on the proliferation, migration and invasion of human endometrial cancer stem-like cells. Gynecologic Oncology 2013, 129 (3), 598-605.

122. Kurra, V.; Krajewski, K. M.; Jagannathan, J.; Giardino, A.; Berlin, S.; Ramaiya, N. Typical and atypical metastatic sites of recurrent endometrial carcinoma. Cancer Imaging 2013, 13 (1), 113.

123. Nassir, M.; Roth, A.; Gasimli, K.; Braicu, E. I.; Fotopoulou, C.; Mawrin, C.; Badakhshi, H.; Warnke, J. P.; Sehouli, J. Is endometrial cancer really a neurophobic tumor? A case report and review of the literature. Anticancer research 2014, 34(1), $249-257$.

124. Thigpen, J. T.; Brady, M. F.; Homesley, H. D.; Malfetano, J.; DuBeshter, B.; Burger, R. A.; Liao, S. J. Phase III trial of doxorubicin with or without cisplatin in advanced endometrial carcinoma: a gynecologic oncology group study. Journal of Clinical Oncology, 22(19), 3902-3908.

125. Gann, P. H., Risk factors for prostate cancer. Reviews in urology 2002, 4 (Suppl 5), S3.

126. Wilson, K. M.; Mucci, L. A. Diet and Lifestyle in Prostate Cancer. In Prostate Cancer, Springer: 2019; pp 1-27.

127. Barnard, R. J. Prostate cancer prevention by nutritional means to alleviate metabolic syndrome. The American journal of clinical nutrition 2007, 86 (3), 889S-893S.

128. Arnold, J.; Isaacs, J. Mechanisms involved in the progression of androgen-independent prostate cancers: it is not only the cancer cell's fault. Endocrine-related cancer 2002, 9 (1), 61-73.

129. Roberts, C. T. IGF-1 and prostate cancer. Biology of IGF-1: Its Interaction with Insulin in Health and Malignant States. In Novartis Foundation symposium, Chichester; New York; John Wiley; 2004, 193-198.

130. Giri, D.; Ozen, M.; Ittmann, M. Interleukin-6 is an autocrine growth factor in human prostate cancer. The American journal of pathology 2001, 159 (6), 2159-2165.

131. Puhr, M.; De Marzo, A.; Isaacs, W.; Lucia, M. S.; Sfanos, K.; Yegnasubramanian, S.; Culig, Z. Inflammation, microbiota, and prostate cancer. European urology focus 2016, 2 (4), 374-382.

132. Crawford, E. D. Epidemiology of prostate cancer. Urology 2003, 62 (6), 3-12.

133. Harbitz, T. B.; Haugen, O. Histology of the prostate in elderly men: a study in an autopsy series. Acta Pathologica Microbiologica Scandinavica Section A Pathology 1972, 80 (6), 756-768.

134. Harvey, H. A Unifying Hypothesis that Links Benign Prostatic Hyperplasia and Prostatic Intraepithelial Neoplasia with Prostate Cancer. Pathology-Research and Practice 1995, 191 (9), 924-934.

135. Bostwick, D. G. Prospective origins of prostate carcinoma: prostatic intraepithelial neoplasia and atypical adenomatous hyperplasia. Cancer 1996, 78 (2), 330-336. 
136. Vukovic, B.; Park, P. C.; Al-Maghrabi, J.; Beheshti, B.; Sweet, J.; Evans, A.; Trachtenberg, J.; Squire, J. Evidence of multifocality of telomere erosion in high-grade prostatic intraepithelial neoplasia (HPIN) and concurrent carcinoma. Oncogene 2003, 22 (13), 19781987.

137. Castro, P.; Giri, D.; Lamb, D.; Ittmann, M. Cellular senescence in the pathogenesis of benign prostatic hyperplasia. The Prostate 2003, 55 (1), 30-38.

138. Zhang, Z.; Rosen, D. G.; Yao, J. L.; Huang, J.; Liu, J. Expression of p14ARF, p15INK4b, p16INK4a, and DCR2 increases during prostate cancer progression. Modern pathology 2006, 19 (10), 1339-1343.

139. Perletti, G.; Montanari, E.; Vral, A.; Gazzano, G.; Marras, E.; Mione, S., Magri, V. Inflammation, prostatitis, proliferative inflammatory atrophy: 'Fertile ground'for prostate cancer development?. Molecular medicine reports 2010, 3 (1), 3-12.

140. Meeker, A. K.; Hicks, J. L.; Platz, E. A.; March, G. E.; Bennett, C. J.; Delannoy, M. J.; De Marzo, A. M. Telomere shortening is an early somatic DNA alteration in human prostate tumorigenesis. Cancer research 2002, 62 (22), 6405-6409.

141. Koeneman, K. S.; Pan, C.-X.; JIN, J.-K.; Pyle, J. M.; Flanigan, R. C.; Shankey, T. V.; Diaz, M. O. Telomerase activity, telomere length, and DNA ploidy in prostatic intraepithelial neoplasia (PIN). The Journal of urology 1998, 160 (4), 1533-1539.

142. Henshall, S. M.; Quinn, D. I.; Lee, C. S.; Head, D. R.; Golovsky, D.; Brenner, P. C.; Delprado, W.; Stricker, P. D.; Grygiel, J. J.; Sutherland, R. L. Overexpression of the cell cycle inhibitor p16INK4A in high-grade prostatic intraepithelial neoplasia predicts early relapse in prostate cancer patients. Clinical cancer research 2001, 7 (3), 544-550.

143. Shen, M. M.; Abate-Shen, C. Molecular genetics of prostate cancer: new prospects for old challenges. Genes \& development 2010, 24 (18), 1967-2000.

144. Kwok, W. K.; Ling, M.-T.; Lee, T.-W.; Lau, T. C.; Zhou, C.; Zhang, X.; Chua, C. W.; Chan, K. W.; Chan, F. L.; Glackin, C. Upregulation of TWIST in prostate cancer and its implication as a therapeutic target. Cancer research 2005, 65 (12), 5153-5162.

145. Kolijn, K.; Verhoef, E. I.; Smid, M.; Böttcher, R.; Jenster, G. W.; Debets, R.; van Leenders, G. Epithelial-mesenchymal transition in human prostate cancer demonstrates enhanced immune evasion marked by IDO1 expression. Cancer research 2018, 78 (16), $4671-4679$.

146. Gravdal, K.; Halvorsen, O. J.; Haukaas, S. A.; Akslen, L. A. A switch from E-cadherin to N-cadherin expression indicates epithelial to mesenchymal transition and is of strong and independent importance for the progress of prostate cancer. Clinical cancer research, 13(23), 7003-7011.

147. Liu, C.; Kelnar, K.; Liu, B.; Chen, X.; Calhoun-Davis, T.; Li, H.; Patrawala, L.; Yan, H.; Jeter, C.; Honorio, S. J. The microRNA miR-34a inhibits prostate cancer stem cells and metastasis by directly repressing CD44. Nature medicine 2011, 17 (2), 211.

148. Shang, Z.; Cai, Q.; Zhang, M.; Zhu, S.; Ma, Y.; Sun, L.; Jiang, N.; Tian, J.; Niu, X.; Chen, J. A switch from CD44+ cell to EMT cell drives the metastasis of prostate cancer. Oncotarget 2015, 6 (2), 1202.

149. Gandaglia, G.; Karakiewicz, P. I.; Briganti, A.; Passoni, N. M.; Schiffmann, J.; Trudeau, V.; Graefen, M.; Montorsi, F.; Sun, M. Impact of the site of metastases on survival in patients with metastatic prostate cancer. European urology 2015, 68 (2), 325-334.

150. Chan, A. T.; Giovannucci, E. L. Primary prevention of colorectal cancer. Gastroenterology 2010, 138 (6), 2029-2043. e10.

151. Frezza, E. E.; Wachtel, M. S.; Chiriva-Internati, M. Influence of obesity on the risk of developing colon cancer. Gut 2006, 55 (2), 285-291.

152. Chen, K.; Nezu, R.; Wasa, M.; Sando, K.; Kamata, S.; Takagi, Y.; Okada, A. Insulin-like growth factor-1 modulation of intestinal epithelial cell restitution. Journal of Parenteral and Enteral Nutrition 1999, 23 (5), S89-S92.

153. Becker, C.; Fantini, M. C.; Schramm, C.; Lehr, H. A.; Wirtz, S.; Nikolaev, A.; Burg, J.; Strand, S.; Kiesslich, R.; Huber, S. TGF- $\beta$ suppresses tumor progression in colon cancer by inhibition of IL-6 signaling. Immunity 2004, 21 (4), 491-501.

154. Rouet-Benzineb, P.; Aparicio, T.; Guilmeau, S.; Pouzet, C.; Descatoire, V.; Buyse, M.; Bado, A. J. Leptin counteracts sodium butyrate-induced apoptosis in human colon cancer HT-29 cells via NF-kB signaling. Journal of Biological Chemistry 2004,279 (16), 16495-16502.

155. Kuhn, K. A.; Manieri, N. A.; Liu, T.-C.; Stappenbeck, T. S. IL-6 stimulates intestinal epithelial proliferation and repair after injury. PloS one 2014, 9 (12), e114195.

156. Lapré, J. A.; De Vries, H. T.; Koeman, J. H.; Van der Meer, R. The antiproliferative effect of dietary calcium on colonic epithelium is mediated by luminal surfactants and dependent on the type of dietary fat. Cancer Research 1993, 53 (4), 784-789.

157. Bruce, W. R.; Giacca, A.; Medline, A. Possible mechanisms relating diet and risk of colon cancer. Cancer Epidemiology Biomarkers and Prevention 2000, 9 (12), 1271-1279.

158. Fleming, M.; Ravula, S.; Tatishchev, S. F.; Wang, H. L. Colorectal carcinoma: pathologic aspects. Journal of gastrointestinal oncology 2012, 3 (3), 153-173.

159. Lakatos, P. L.; Lakatos, L. Risk for colorectal cancer in ulcerative colitis: changes, causes and management strategies. World journal of gastroenterology 2008, 14 (25), 3937.

160. Kolligs, F. T. Diagnostics and epidemiology of colorectal cancer. Visceral medicine 2016, 32 (3), 158-164.

161. Cusack, J. C.; Giacco, G. G.; Cleary, K.; Davidson, B. S.; Izzo, F.; Skibber, J.; Yen, J.; Curley, S. A. Survival factors in 186 patients younger than 40 years old with colorectal adenocarcinoma. Journal of the American College of Surgeons 1996, 183 (2), 105-112.

162. Hyman, N. H.; Anderson, P.; Blasyk, H. Hyperplastic polyposis and the risk of colorectal cancer. Diseases of the colon and rectum 2004, 47 (12), 2101-2104.

163. Hardikar, S.; Burnett-Hartman, A. N.; Phipps, A. I.; Upton, M. P.; Zhu, L.-C.; Newcomb, P. A. Telomere length differences between colorectal polyp subtypes: a colonoscopy-based case-control study. BMC cancer 2018, 18 (1), 513.

164. Tang, R.; Cheng, A.-J.; Wang, J.-Y.; Wang, T.-C. Close correlation between telomerase expression and adenomatous polyp progression in multistep colorectal carcinogenesis. Cancer research 1998 58(18), 4052-4054. 
165. Dorudi, S.; Sheffield, J.; Poulsom, R.; Northover, J.; Hart, I. E-cadherin expression in colorectal cancer. An immunocytochemical and in situ hybridization study. The American journal of pathology 1993, 142 (4), 981.

166. Calon, A.; Lonardo, E.; Berenguer-Llergo, A.; Espinet, E.; Hernando-Momblona, X.; Iglesias, M.; Sevillano, M.; Palomo-Ponce, S.; Tauriello, D. V.; Byrom, D. Stromal gene expression defines poor-prognosis subtypes in colorectal cancer. Nature genetics 2015, 47 (4), 320.

167. Francí, C.; Gallen, M.; Alameda, F.; Baro, T.; Iglesias, M.; Virtanen, I.; de Herreros, A. G. Snaill protein in the stroma as a new putative prognosis marker for colon tumours. PLoS One 2009, 4 (5).

168. Gomez, I.; Peña, C.; Herrera, M.; Muñoz, C.; Larriba, M. J.; Garcia, V.; Dominguez, G.; Silva, J.; Rodriguez, R.; de Herreros, A. G. TWIST1 is expressed in colorectal carcinomas and predicts patient survival. PloS one 2011, 6 (3).

169. Zhang, G.-J.; Zhou, T.; Tian, H.-P.; Liu, Z.-L.; Xia, S.-S. High expression of ZEB1 correlates with liver metastasis and poor prognosis in colorectal cancer. Oncology letters 2013, 5 (2), 564-568.

170. Skog, M.; Bono, P.; Lundin, M.; Lundin, J.; Louhimo, J.; Linder, N.; Petrova, T. V.; Andersson, L. C.; Joensuu, H.; Alitalo, K. Expression and prognostic value of transcription factor PROX1 in colorectal cancer. British journal of cancer 2011, 105 (9), $1346-1351$.

171. Zhou, J.-Y.; Chen, M.; Ma, L.; Wang, X.; Chen, Y.-G.; Liu, S.-L. Role of CD44high/CD133high HCT-116 cells in the tumorigenesis of colon cancer. Oncotarget 2016, 7 (7), 7657.

172. Brabletz, T.; Jung, A.; Spaderna, S.; Hlubek, F.; Kirchner, T. Migrating cancer stem cells an integrated concept of malignant tumour progression. Nature Reviews Cancer 2005, 5 (9), 744-749.

173. Leng, Z.; Xia, Q.; Chen, J.; Li, Y.; Xu, J.; Zhao, E.; Zheng, H.; Ai, W.; Dong, J. Biochemistry, Lgr5+ CD44+ EpCAM+ strictly defines cancer stem cells in human colorectal cancer. Cellular Physiology and Biochemistry 2018, 46 (2), 860-872.

174. Patanaphan, V.; Salazar, O. Colorectal cancer: metastatic patterns and prognosis. Southern medical journal 1993, 86 (1), $38-41$.

175. Kabbinavar, F. F.; Hambleton, J.; Mass, R. D.; Hurwitz, H. I.; Bergsland, E.; Sarkar, S. Combined analysis of efficacy: the addition of bevacizumab to fluorouracil/leucovorin improves survival for patients with metastatic colorectal cancer. Journal of clinical oncology 2005, 23 (16), 3706-3712.

176. Khan, N.; Afaq, F.; Mukhtar, H. Lifestyle as risk factor for cancer: Evidence from human studies. Cancer letters 2010, 293 (2), $133-$ 143.

177. Masubuchi, T.; Koyama, S.; Sato, E.; Takamizawa, A.; Kubo, K.; Sekiguchi, M.; Nagai, S.; Izumi, T. Smoke extract stimulates lung epithelial cells to release neutrophil and monocyte chemotactic activity. The American journal of pathology 1998, 153 (6), $1903-1912$.

178. Zhao, P.; Fu, J.; Yao, B.; Song, Y.; Mi, L.; Li, Z.; Shang, L.; Hao, W.; Zhou, Z. In vitro malignant transformation of human bronchial epithelial cells induced by benzo (a) pyrene. Toxicology in Vitro 2012, 26 (2), 362-368.

179. Yang, Y.; Yu, C.; Zhou, M.; Pang, N.; Li, N.; Nie, H.; Liao, J.; Bai, Y.; Liu, H. Metabolic study of 4-(methylnitrosamino)-1-(3pyridyl)-1-butanone to the enantiomers of 4-(methylnitrosamino)-1-(3-pyridyl)-1-butanol in vitro in human bronchial epithelial cells using chiral capillary electrophoresis. Journal of Chromatography 2011, 1218 (37), 6505-6510.

180. Hecht, S. S.; Isaacs, S.; Trushin, N. Lung tumor induction in A/J mice by the tobacco smoke carcinogens 4-(methylnitrosamino)-1(3-pyridyl)-l-butanone and benzo [a] pyrene: a potentially useful model for evaluation of chemopreventive agents. Carcinogenesis 1994, 15 (12), 2721-2725.

181. Sevenoaks, M. J.; Stockley, R. A. Chronic Obstructive Pulmonary Disease, inflammation and co-morbidity a common inflammatory phenotype? Respiratory research 2006, 7 (1), 70.

182. Smith, C. J.; Perfetti, T. A.; King, J. A. Perspectives on pulmonary inflammation and lung cancer risk in cigarette smokers. Inhalation toxicology 2006, 18 (9), 667-677.

183. Petty, T. L., Lung cancer and chronic obstructive pulmonary disease. Hematology/oncology clinics of North America 1997, 11 (3), 531-541.

184. Owonikoko, T. K.; Ragin, C. C.; Belani, C. P.; Oton, A. B.; Gooding, W. E.; Taioli, E.; Ramalingam, S. S. Lung cancer in elderly patients: an analysis of the surveillance, epidemiology, and end results database. Journal of clinical oncology 2007, 25 (35), $5570-5577$.

185. Kreuzer, M.; Kreienbrock, L.; Müller, K. M.; Gerken, M.; Wichmann, E. Histologic types of lung carcinoma and age at onset. Cancer: Interdisciplinary International Journal of the American Cancer Society 1999, 85 (9), 1958-1965.

186. Kerr, K. Pulmonary preinvasive neoplasia. Journal of clinical pathology 2001, 54 (4), 257-271.

187. Chapman, A.; Kerr, K. The association between atypical adenomatous hyperplasia and primary lung cancer. British journal of cancer 2000, $83(5), 632$.

188. Kurasono, Y.; Ito, T.; Kameda, Y.; Nakamura, N.; Kitamura, H. Expression of cyclin D1, retinoblastoma gene protein, and p16 MTS1 protein in atypical adenomatous hyperplasia and adenocarcinoma of the lung. Virchows Archiv, 1998, 432 (3), 207-215.

189. Yashima, K.; Litzky, L. A.; Kaiser, L.; Rogers, T.; Lam, S.; Wistuba, I. I.; Milchgrub, S.; Srivastava, S.; Piatyszek, M. A.; Shay, J. W. Telomerase expression in respiratory epithelium during the multistage pathogenesis of lung carcinomas. Cancer research 1997,57 (12), 2373-2377.

190. Mori, M.; Rao, S. K.; Popper, H. H.; Cagle, P. T.; Fraire, A. E. Atypical adenomatous hyperplasia of the lung: a probable forerunner in the development of adenocarcinoma of the lung. Modern Pathology 2001, 14 (2), $72-84$.

191. Kawai, T.; Hiroi, S.; Nakanishi, K.; Meeker, A. K. Telomere length and telomerase expression in atypical adenomatous hyperplasia and small bronchioloalveolar carcinoma of the lung. American journal of clinical pathology 2007, 127 (2), 254-262.

192. Kase, S.; Sugio, K.; Yamazaki, K.; Okamoto, T.; Yano, T.; Sugimachi, K. Expression of E-cadherin and $\beta$-catenin in human nonsmall cell lung cancer and the clinical significance. Clinical Cancer Research 2000, 6 (12), 4789-4796.

193. Chae, Y. K.; Chang, S.; Ko, T.; Anker, J.; Agte, S.; Iams, W.; Choi, W. M.; Lee, K.; Cruz, M. Epithelial-mesenchymal transition (EMT) signature is inversely associated with T-cell infiltration in non-small cell lung cancer (NSCLC). Scientific reports 2018, 8 (1), 1-8. 
194. Chiou, S.-H.; Wang, M.-L.; Chou, Y.-T.; Chen, C.-J.; Hong, C.-F.; Hsieh, W.-J.; Chang, H.-T.; Chen, Y.-S.; Lin, T.-W.; Hsu, H.-S. Coexpression of Oct4 and Nanog enhances malignancy in lung adenocarcinoma by inducing cancer stem cell-like properties and epithelial-mesenchymal transdifferentiation. Cancer research 2010, 70 (24), 10433-10444.

195. Bertolini, G.; Roz, L.; Perego, P.; Tortoreto, M.; Fontanella, E.; Gatti, L.; Pratesi, G.; Fabbri, A.; Andriani, F.; Tinelli, S. Highly tumorigenic lung cancer $\mathrm{CD} 133+$ cells display stem-like features and are spared by cisplatin treatment. Proceedings of the National Academy of Sciences 2009, 106 (38), 16281-16286.

196. Riihimäki, M.; Hemminki, A.; Fallah, M.; Thomsen, H.; Sundquist, K.; Sundquist, J.; Hemminki, K. Metastatic sites and survival in lung cancer. Lung cancer 2014, 86 (1), 78-84.

197. Lo, A.-C.; Soliman, A. S.; El-Ghawalby, N.; Abdel-Wahab, M.; Fathy, O.; Khaled, H. M.; Omar, S.; Hamilton, S. R.; Greenson, J. K.; Abbruzzese, J. Lifestyle, occupational, and reproductive factors in relation to pancreatic cancer risk. Pancreas 2007, 35(2), $120-129$.

198. Lochan, R.; Reeves, H. L.; Daly, A. K.; Charnley, R. M. The role of tobacco-derived carcinogens in pancreas cancer. International Scholarly Research Notices 2011.

199. Yadav, D.; Lowenfels, A. B. The epidemiology of pancreatitis and pancreatic cancer. Gastroenterology 2013, 144 (6), $1252-1261$.

200. Momi, N.; Kaur, S.; Krishn, S.; Batra, S. K. Discovering the route from inflammation to pancreatic cancer. Minerva gastroenterologica e dietologica 2012, 58 (4), 283.

201. Fesinmeyer, M. D.; Austin, M. A.; Li, C. I.; De Roos, A. J.; Bowen, D. J. Differences in survival by histologic type of pancreatic cancer. Cancer Epidemiology and Prevention Biomarkers 2005, 14 (7), 1766-1773.

202. Kolodecik, T.; Shugrue, C.; Ashat, M.; Thrower, E. C. Risk factors for pancreatic cancer: underlying mechanisms and potential targets. Frontiers in physiology 2014, 4, 415.

203. Brat, D. J.; Lillemoe, K. D.; Yeo, C. J.; Warfield, P. B.; Hruban, R. H. Progression of pancreatic intraductal neoplasias to infiltrating adenocarcinoma of the pancreas. The American journal of surgical pathology 1998, 22 (2), 163-169.

204. Zińczuk, J.; Zaręba, K.; Guzińska-Ustymowicz, K.; Kędra, B.; Kemona, A.; Pryczynicz, A. p16, p21, and p53 proteins play an important role in development of pancreatic intraepithelial neoplastic. Irish Journal of Medical Science 2018, 187 (3), $629-637$.

205. Van Heek, N. T.; Meeker, A. K.; Kern, S. E.; Yeo, C. J.; Lillemoe, K. D.; Cameron, J. L.; Offerhaus, G. J. A.; Hicks, J. L.; Wilentz, R. E.; Goggins, M. G. Telomere shortening is nearly universal in pancreatic intraepithelial neoplasia. The American journal of pathology 2002, $161(5), 1541-1547$.

206. Hashimoto, Y.; Murakami, Y.; Uemura, K.; Hayashidani, Y.; Sudo, T.; Ohge, H.; Fukuda, E.; Shimamoto, F.; Sueda, T.; Hiyama, E. Telomere shortening and telomerase expression during multistage carcinogenesis of intraductal papillary mucinous neoplasms of the pancreas. Journal of Gastrointestinal Surgery 2008, 12 (1), 17-28.

207. Hong, S.-M.; Li, A.; Olino, K.; Wolfgang, C. L.; Herman, J. M.; Schulick, R. D.; Iacobuzio-Donahue, C.; Hruban, R. H.; Goggins, M. Loss of E-cadherin expression and outcome among patients with resectable pancreatic adenocarcinomas. Modern pathology 2011, 24 (9), 1237-1247

208. Lawlor, R. T.; Veronese, N.; Nottegar, A.; Malleo, G.; Smith, L.; Demurtas, J.; Cheng, L.; Wood, L. D.; Silvestris, N.; Salvia, R. Prognostic role of high-grade tumor budding in pancreatic ductal adenocarcinoma: a systematic review and meta-analysis with a focus on epithelial to mesenchymal transition. Cancers 2019, 11 (1), 113.

209. Li, C.; Heidt, D. G.; Dalerba, P.; Burant, C. F.; Zhang, L.; Adsay, V.; Wicha, M.; Clarke, M. F.; Simeone, D. M. Identification of pancreatic cancer stem cells. Cancer research 2007, 67 (3), 1030-1037.

210. Rhim, A. D.; Mirek, E. T.; Aiello, N. M.; Maitra, A.; Bailey, J. M.; McAllister, F.; Reichert, M.; Beatty, G. L.; Rustgi, A. K.; Vonderheide, R. H. EMT and dissemination precede pancreatic tumor formation. Cell 2012, 148 (1-2), 349-361.

211. Krebs, A. M.; Mitschke, J.; Losada, M. L.; Schmalhofer, O.; Boerries, M.; Busch, H.; Boettcher, M.; Mougiakakos, D.; Reichardt, W.; Bronsert, P. The EMT-activator Zeb1 is a key factor for cell plasticity and promotes metastasis in pancreatic cancer. Nature cell biology 2017, 19 (5), 518-529.

212. Poruk, K. E.; Blackford, A. L.; Weiss, M. J.; Cameron, J. L.; He, J.; Goggins, M.; Rasheed, Z. A.; Wolfgang, C. L.; Wood, L. D. Circulating tumor cells expressing markers of tumor-initiating cells predict poor survival and cancer recurrence in patients with pancreatic ductal adenocarcinoma. Clinical cancer research 2017, 23 (11), 2681-2690.

213. Peixoto, R. D. A.; Speers, C.; McGahan, C. E.; Renouf, D. J.; Schaeffer, D. F.; Kennecke, H. F. Prognostic factors and sites of metastasis in unresectable locally advanced pancreatic cancer. Cancer medicine 2015, 4 (8), 1171-1177.

214. Allendorf, J. D.; Lauerman, M.; Bill, A.; DiGiorgi, M.; Goetz, N.; Vakiani, E.; Remotti, H.; Schrope, B.; Sherman, W.; Hall, M. Neoadjuvant chemotherapy and radiation for patients with locally unresectable pancreatic adenocarcinoma: feasibility, efficacy, and survival. Journal of Gastrointestinal Surgery 2008, 12 (1), 91-100.

215. Tanaka, T.; Miyazawa, K.; Tsukamoto, T.; Kuno, T.; Suzuki, K. Pathobiology and chemoprevention of bladder cancer. Journal of oncology 2011.

216. Saginala, K.; Barsouk, A.; Aluru, J. S.; Rawla, P.; Padala, S. A.; Barsouk, A. Epidemiology of Bladder Cancer. Medical Sciences 2020, 8 (1), 15.

217. Letašiová, S.; Medved’ová, A.; Šovčíková, A.; Dušinská, M.; Volkovová, K.; Mosoiu, C.; Bartonová, A. Bladder cancer, a review of the environmental risk factors. Environmental Health 2012, 11 (1), 1.

218. Jin, F.; Thaiparambil, J.; Donepudi, S. R.; Vantaku, V.; Piyarathna, D. W. B.; Maity, S.; Krishnapuram, R.; Putluri, V.; Gu, F.; Purwaha, P. Tobacco-specific carcinogens induce hypermethylation, DNA adducts, and DNA damage in bladder cancer. Cancer Prevention Research 2017, 10 (10), 588-597.

219. Mostafa, M. H.; Sheweita, S.; O'Connor, P. J. Relationship between schistosomiasis and bladder cancer. Clinical Microbiology Reviews 1999, 12 (1), 97-111. 
220. Rosin, M. P.; Anwar, W. A.; Ward, A. Inflammation, chromosomal instability, and cancer: the schistosomiasis model. Cancer Research 1994, 54 (7 Supplement), 1929s-1933s.

221. Michaud, D. S. In Chronic inflammation and bladder cancer. Urologic oncology: Seminars and original investigations 2007, 25 (3), 260-268, Elsevier.

222. Aliramaji, A.; Kaseean, A.; Pasha, Y. R. Y.; Shafi, H.; Kamali, S.; Safari, M.; Moudi, E. Age distribution types of bladder cancers and their relationship with opium consumption and smoking. Caspian journal of internal medicine 2015, 6 (2), 82.

223. Telli, O.; Sarici, H.; Ozgur, B. C.; Doluoglu, O. G.; Sunay, M. M.; Bozkurt, S.; Eroglu, M. Urothelial cancer of bladder in young versus older adults: clinical and pathological characteristics and outcomes. The Kaohsiung journal of medical sciences 2014, 30 (9), 466470 .

224. Edgecombe, A.; Nguyen, B. N.; Djordjevic, B.; Belanger, E. C.; Mai, K. Utility of cytokeratin 5/6, cytokeratin 20, and p16 in the diagnosis of reactive urothelial atypia and noninvasive component of urothelial neoplasia. Applied immunohistochemistry and molecular morphology 2012, 20 (3), 264-271.

225. Sanfrancesco, J.; Jones, J. S.; Hansel, D. E. Diagnostically challenging cases: what are atypia and dysplasia?. The Urologic clinics of North America 2013, 40 (2), 281.

226. Williamson, S. R.; Zhang, S.; Lopez-Beltran, A.; Montironi, R.; Wang, M.; Cheng, L. Telomere shortening distinguishes inverted urothelial neoplasms. Histopathology 2013, 62 (4), 595-601.

227. Morii, A.; Komiya, A.; Okumura, A.; Fuse, H. Telomerase activity in bladder cancer tissue. Experimental and therapeutic medicine 2010, 1 (1), 85-88.

228. Bryan, R. T.; Tselepis, C. Cadherin switching and bladder cancer. The Journal of urology 2010, 184 (2), 423-431.

229. Paliwal, P.; Arora, D.; Mishra, A. K. Epithelial mesenchymal transition in urothelial carcinoma: twist in the tale. Indian Journal of Pathology and Microbiology 2012, 55 (4), 443.

230. Choi, W.; Porten, S.; Kim, S.; Willis, D.; Plimack, E. R.; Hoffman-Censits, J.; Roth, B.; Cheng, T.; Tran, M.; Lee, I.-L. Identification of distinct basal and luminal subtypes of muscle-invasive bladder cancer with different sensitivities to frontline chemotherapy. Cancer cell 2014, 25 (2), 152-165.

231. Li, Y.; Lin, K.; Yang, Z.; Han, N.; Quan, X.; Guo, X.; Li, C. Bladder cancer stem cells: Clonal origin and therapeutic perspectives. Oncotarget 2017, 8 (39), 66668.

232. Kuncova, J.; Urban, M.; Mandys, V. Expression of CD44s and CD44v6 in transitional cell carcinomas of the urinary bladder: comparison with tumour grade, proliferative activity and p53 immunoreactivity of tumour cells. Apmis 2007, 115 (11), 1194-1205.

233. Hedegaard, J.; Lamy, P.; Nordentoft, I.; Algaba, F.; Høyer, S.; Ulhøi, B. P.; Vang, S.; Reinert, T.; Hermann, G. G.; Mogensen, K. Comprehensive transcriptional analysis of early-stage urothelial carcinoma. Cancer cell 2 2016, 30 (1), 27-42.

234. Ecke, T.; Gerullis, H.; Bartel, P.; Koch, S.; Ruttloff, J. Palliative chemotherapy with gemcitabine, paclitaxel, and cisplatin as firstline treatment following gemcitabine monotherapy for patients with transitional cell carcinoma of the urothelium. The Italian journal of urology and nephrology 2009, 61 (1), 1-8.

235. El-Serag, H. B.; Rudolph, K. L. Hepatocellular carcinoma: epidemiology and molecular carcinogenesis. Gastroenterology 2007, 132 (7), 2557-2576.

236. Srivatanakul, P.; Sriplung, H.; Deerasamee, S. Epidemiology of liver cancer: an overview. Asian Pacific journal of cancer prevention 2004, 5 (2), 118-125.

237. Karin, M.; Dhar, D. Liver carcinogenesis: from naughty chemicals to soothing fat and the surprising role of NRF2. Carcinogenesis 2016, 37 (6), 541-546.

238. Testino, G. The burden of cancer attributable to alcohol consumption. Maedica 2011, 6 (4), 313.

239. Villanueva, A.; Luedde, T. The transition from inflammation to cancer in the liver. Clinical liver disease 2016, 8 (4), 89-93.

240. Petrick, J. L.; Braunlin, M.; Laversanne, M.; Valery, P. C.; Bray, F.; McGlynn, K. A. International trends in liver cancer incidence, overall and by histologic subtype, 1978-2007. International journal of cancer 2016, 139 (7), 1534-1545.

241. Nishimoto, A.; Miura, N.; Oshimura, M. Clinical significance of telomerase activity in precancerous lesion of the liver (adenomatous hyperplasia). Japanese journal of clinical medicine 1998, 56 (5), 1244-1247.

242. Pacheco-Rivera, R.; Fattel-Fazenda, S.; Arellanes-Robledo, J.; Silva-Olivares, A.; Alemán-Lazarini, L.; Rodríguez-Segura, M.; Pérez-Carreón, J.; Villa-Treviño, S.; Shibayama, M.; Serrano-Luna, J. Double staining of $\beta$-galactosidase with fibrosis and cancer markers reveals the chronological appearance of senescence in liver carcinogenesis induced by diethylnitrosamine. Toxicology letters 2016, 241, 19-31.

243. Leong, T. Y.-M.; Leong, A. S.-Y. Epidemiology and carcinogenesis of hepatocellular carcinoma. Hpb 2005, 7 (1), 5-15.

244. Venturi, A.; Piscaglia, F.; Vidili, G.; Flori, S.; Righini, R.; Golfieri, R.; Bolondi, L. Diagnosis and management of hepatic focal nodular hyperplasia. Journal of ultrasound 2007, 10 (3), 116-127.

245. Nault, J. C.; Mallet, M.; Pilati, C.; Calderaro, J.; Bioulac-Sage, P.; Laurent, C.; Laurent, A.; Cherqui, D.; Balabaud, C.; ZucmanRossi, J. High frequency of telomerase reverse-transcriptase promoter somatic mutations in hepatocellular carcinoma and preneoplastic lesions. Nature communications 2013, 4, 2218.

246. Hui, A.; Sakamoto, M.; Kanai, Y.; Ino, Y.; Gotoh, M.; Yokota, J.; Hirohashi, S. Inactivation of p16INK4 in hepatocellular carcinoma. Hepatology 1996, 24 (3), 575-579.

247. Zhai, B.; Yan, H.-X.; Liu, S.-Q.; Chen, L.; Wu, M.-C.; Wang, H.-Y. Reduced expression of E-cadherin/catenin complex in hepatocellular carcinomas. World journal of gastroenterology 2008, 14 (37), 5665.

248. Yang, M. H.; Chen, C. L.; Chau, G. Y.; Chiou, S. H.; Su, C. W.; Chou, T. Y.; Peng, W. L.; Wu, J. C. Comprehensive analysis of the independent effect of twist and snail in promoting metastasis of hepatocellular carcinoma. Hepatology 2009, 50 (5), 1464-1474. 
249. Yamada, S.; Okumura, N.; Wei, L.; Fuchs, B. C.; Fujii, T.; Sugimoto, H.; Nomoto, S.; Takeda, S.; Tanabe, K. K.; Kodera, Y. Epithelial to mesenchymal transition is associated with shorter disease-free survival in hepatocellular carcinoma. Annals of surgical oncology 2014, 21 (12), 3882-3890.

250. Li, Y.; Xu, S.; Li, J.; Han, K.; Pi, H.; Zheng, L.; Zuo, G.; Huang, X.; Li, H.; Zhao, H. Epithelial mesenchymal transition markers expressed in circulating tumor cells in hepatocellular carcinoma patients with different stages of disease. Cell death and disease 2013, 4 (10), e831-e831.

251. Huaman, J.; Bach, C.; Ilboudo, A.; Ogunwobi, O. Epithelial-to-mesenchymal transition in hepatocellular carcinoma. In Precision Molecular Pathology of Liver Cancer 2018, 131-152, Springer.

252. Wan, S.; Zhao, E.; Kryczek, I.; Vatan, L.; Sadovskaya, A.; Ludema, G.; Simeone, D. M.; Zou, W.; Welling, T. H. Tumor-associated macrophages produce interleukin 6 and signal via STAT3 to promote expansion of human hepatocellular carcinoma stem cells. Gastroenterology 2014, 147 (6), 1393-1404.

253. Fernando, J.; Malfettone, A.; Cepeda, E. B.; Vilarrasa-Blasi, R.; Bertran, E.; Raimondi, G.; Fabra, À.; Alvarez-Barrientos, A.; Fernández-Salguero, P.; Fernández-Rodríguez, C. M. A mesenchymal-like phenotype and expression of CD44 predict lack of apoptotic response to sorafenib in liver tumor cells. International journal of cancer 2015, 136 (4), 161-172.

254. Cai, H.; Wang, H.; Li, Z.; Lin, J.; Yu, J. The prognostic analysis of different metastatic patterns in extensive-stage small-cell lung cancer patients: a large population-based study. Future Oncology 2018, 14 (14), 1397-1407.

255. Crissien, A. M.; Frenette, C. Current management of hepatocellular carcinoma. Gastroenterology and hepatology 2014, 10 (3), 153.

256. Carr, B. I.; Iwatsuki, S.; Starzl, T. E.; Selby, R.; Madariaga, J. Regional cancer chemotherapy for advanced stage hepatocellular carcinoma. Journal of surgical oncology 1993, 3, 100.

257. Rock, C. L.; Michael, C. W.; Reynolds, R. K.; Ruffin, M. T. Prevention of cervix cancer. Critical reviews in oncology/hematology 2000, 33 (3), 169-185.

258. Castrilli, G.; Tatone, D.; Diodoro, M.; Rosini, S.; Piantelli, M.; Musiani, P. Interleukin 1alpha and interleukin 6 promote the in vitro growth of both normal and neoplastic human cervical epithelial cells. British journal of cancer 1997, 75 (6), 855.

259. Deivendran, S.; Marzook, K. H.; Pillai, M. R. The role of inflammation in cervical cancer. Inflammation and Cancer 2014, 377-399.

260. Yost, S.; Hoekstra, A. Cervical cancer in women over 65: An analysis of screening. Gynecologic oncology reports 2018, $25,48-51$.

261. Rozario, S. d.; Silva, I. F. d.; Koifman, R. J.; Silva, I. F. Characterization of women with cervical cancer assisted at Inca by histological type. Revista de saude publica, 53, 88.2019, 53, 88 .

262. Vink, M. A.; Bogaards, J. A.; van Kemenade, F. J.; de Melker, H. E.; Meijer, C. J.; Berkhof, J. Clinical progression of high-grade cervical intraepithelial neoplasia: estimating the time to preclinical cervical cancer from doubly censored national registry data. American journal of epidemiology 2013, 178 (7), 1161-1169.

263. Liu, Y.; Alqatari, M.; Sultan, K.; Ye, F.; Gao, D.; Sigel, K.; Zhang, D.; Kalir, T. Using p16 immunohistochemistry to classify morphologic cervical intraepithelial neoplasia 2: correlation of ambiguous staining patterns with HPV subtypes and clinical outcome. Human pathology 2017, 66, 144-151.

264. Maskey, N.; Thapa, N.; Maharjan, M.; Shrestha, G.; Maharjan, N.; Cai, H.; Liu, S. Infiltrating CD4 and CD8 lymphocytes in HPV infected uterine cervical milieu. Cancer management and research 2019, 11, 7647.

265. Meeker, A. K.; Hicks, J. L.; Iacobuzio-Donahue, C. A.; Montgomery, E. A.; Westra, W. H.; Chan, T. Y.; Ronnett, B. M.; De Marzo, A. M. Telomere length abnormalities occur early in the initiation of epithelial carcinogenesis. Clinical Cancer Research 2004, 10 (10), 3317-3326.

266. Cheah, P.; Looi, L.; Ng, M. H.; Sivanesaratnam, V. Telomerase activation and human papillomavirus infection in invasive uterine cervical carcinoma in a set of Malaysian patients. Journal of clinical pathology 2002, 55 (1), 22-26.

267. Lee, M.-Y.; Chou, C.-Y.; Tang, M.-J.; Shen, M.-R. Epithelial-mesenchymal transition in cervical cancer: correlation with tumor progression, epidermal growth factor receptor overexpression, and snail up-regulation. Clinical Cancer Research 2008 14(15), 47434750 .

268. Lin, J.; Liu, X.; Ding, D. Evidence for epithelial-mesenchymal transition in cancer stem-like cells derived from carcinoma cell lines of the cervix uteri. International journal of clinical and experimental pathology 2015, 8 (1), 847.

269. Ye, F.; Zhou, C.; Cheng, Q.; Shen, J.; Chen, H. Stem-cell-abundant proteins Nanog, Nucleostemin and Musashil are highly expressed in malignant cervical epithelial cells. BMC cancer 2008, 8 (1), 108.

270. Tyagi, A.; Vishnoi, K.; Mahata, S.; Verma, G.; Srivastava, Y.; Masaldan, S.; Roy, B. G.; Bharti, A. C.; Das, B. C. Cervical cancer stem cells selectively overexpress HPV oncoprotein E6 that controls stemness and self-renewal through upregulation of HES1. Clinical Cancer Research 2016, 22 (16), 4170-4184.

271.Yin, Z.; Tang, H.; Li, L.; Ni, J.; Yuan, S.; Lou, H.; Chen, M. Impact of sites versus number of metastases on survival of patients with organ metastasis from newly diagnosed cervical cancer. Cancer management and research 2019, 11, 7759. 